\title{
Three-dimensional/Four-dimensional Sonography moved Prenatal Diagnosis of Fetal Anomalies from the Second to the First Trimester of Pregnancy
}

\author{
Ritsuko K Pooh, Asim Kurjak
}

\begin{abstract}
The introduction of three-dimensional (3D)/four-dimensional (4D) sonography with high-frequency transvaginal transducer has resulted in remarkable progress in ultrasonographic visualization of early embryos and fetuses and development of new fields of 3D sonoembryology. With the proper use of this new diagnostic modality and with experienced examiner, both structural and functional development in the first trimester of gestation can be assessed more objectively and reliable.

Indeed, new technology moved embryology from postmortem studies to the in vivo environment. Furthermore, there are good reasons to believe that 3D/4D sonography moved prenatal diagnosis of fetal abnormalities from the second to the first trimester of pregnancy. We will try to illustrate it with the number of convincing figures.
\end{abstract}

Keywords: Three-dimensional/four-dimensional sonography, Three-dimensional sonoembryology, Fetal anomalies.

\begin{abstract}
How to cite this article: Pooh RK, Kurjak A. Three-dimensional/ Four-dimensional Sonography moved Prenatal Diagnosis of Fetal Anomalies from the Second to the First Trimester of Pregnancy. Donald School J Ultrasound Obstet Gynecol 2012;6(4):376-390.
\end{abstract}

\section{Source of support $\mathrm{Nil}$}

Conflict of interest: None declared

\section{VISUALIZATION OF NORMAL EMBRYO}

Recent introduction of three-dimensional (3D) and fourdimensional (4D) ultrasounds combined with the transvaginal approach has produced more objective and accurate information on embryonal and early fetal development. ${ }^{1-4}$ Figure 1 shows a gestational sac at 4 weeks of gestation and the yolk sac visualization at 5 weeks of gestation. Demonstration of small embryo less than $10 \mathrm{~mm}$ of greatest length has been difficult and not visualized in detail. Figures 2 and 3 show $5.5 \mathrm{~mm}$ long embryo with yolk sac at 6 weeks of gestation and $18.3 \mathrm{~mm}$ crown-rump length (CRL ) embryo at 8 weeks of gestation respectively, depicted by using the most up-date $3 \mathrm{D}$ equipment with highfrequency transvaginal transducer (V oluson ${ }^{\circledR} \mathrm{E} 8$ with $12 \mathrm{MHz} / 256$ element vaginal probe, GE Healthcare, Milwaukee, USA ). Early neural tube and premature spinal cord are successfully demonstrated in a small embryo.
Figure 4 is macrographic images of an aborted specimen taken just after abortion. Premature spinal cord is visualized on the back, which is compatible with 3D image on Figure 3. Figure 5 shows the development of spinal cord in embryonal size of $5.5,18.3$ and $26.3 \mathrm{~mm}^{7}$ Thereafter, the vertebral bony structure can be visualized from 11 weeks of gestation and gradual closure of bilateral laminae caudally from the cervical region (Fig. 6).

The development of the embryonic circulation became visible by 3D power Doppler imaging technology. ${ }^{5}$ Figure 7 illustrates the vascular network of an embryo at 7 weeks of gestation. In 1993 and 1994, color Doppler detection and assessment of brain vessels in the early fetus using a transvaginal approach was reported. ${ }^{6,7}$ Clear visualization by transvaginal power Doppler of the common carotid arteries, internal and external carotid arteries, and middle cerebral arteries at 12 weeks of gestation was reported in 1996. ${ }^{8}$ By using 3D power Doppler technology, the vascular anatomy can now be imaged clearly by identification of the common carotid arteries, internal carotid arteries, circle of Willis and middle cerebral arteries (Fig. 8).

The utilization of postprocessing algorithms, such as maximum mode can be used to demonstrate the fetal skeleton. Chaoui et $\mathrm{al}^{9}$ reported clear 3D images for the identification of an abnormally wide metopic suture in the second trimester of pregnancy. How ever, rapid ossification of the craniofacial bones occurs during the first trimester of pregnancy. We demonstrate in this paper the identification of the craniofacial skeleton from 10 weeks of gestation onward. Figures 9 and 10 show early fetal craniofacial bony structures at 11 and 14 weeks, respectively, using the maximum mode algorithm. The difference of frontal bone morphology between 11 and 14 weeks demonstrates membranous ossification of the cranium at this stage. Figure 11 demonstrates the structure of the skull in the occipital region at 13 weeks of gestation.

During the early embryonic period, the central nervous system (CNS) anatomy rapidly changes in appearance. $M$ agnetic resonance images show remarkable change of CNS appearance in a short period between Carnegie stages

Note This article has been previously published in the J ournal of M aternal-F etal and N eonatal M edicine 2012;25(5):433-55. W ith permission of the publisher and Chief Editor it could be published in the Donald School J ournal of Ultrasound in Obstetrics and Gynecology. 


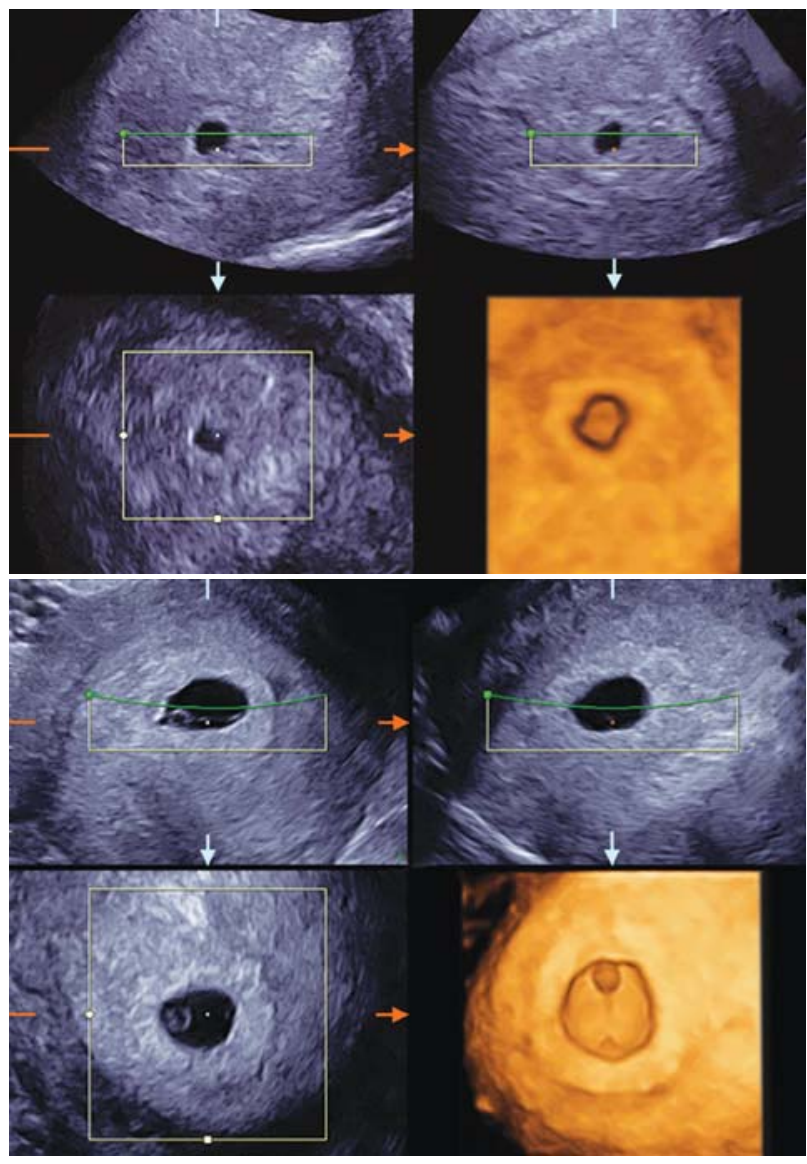

Fig. 1: Development of gestational sac (4 and 5 weeks of gestation) (left) 4 weeks (2 weeks after conception) of gestation. Three orthogonal views and 3D constructed image demonstrated early gestational sac (right). The beginning of 5 weeks, yolk sac is detectable inside gestational sac

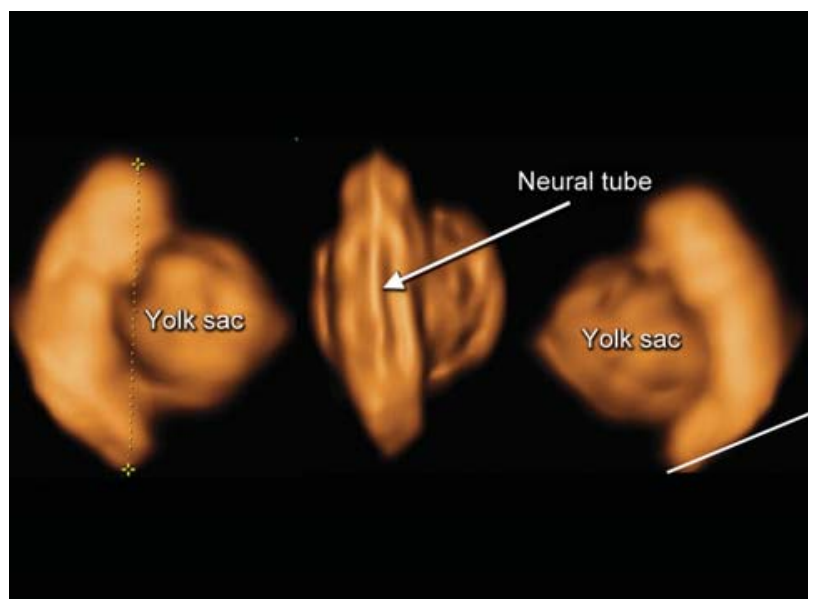

Fig. 2: 3D reconstructed image of the yolk sac and $5.5 \mathrm{~mm}$ CRL-embryo (6 weeks of gestation). Normal 6-week embryo (CRL $5.5 \mathrm{~mm}$ ) and yolk sac. Occipital view shows the neural tube on the embryonal back

18 and 23. Detailed cerebrospinal structure by magnetic resonance imaging at Carnegie stage 23 is visualized in Figure 12.

3D sonography using transvaginal sonography with high-resolution probes allows imaging of early structures

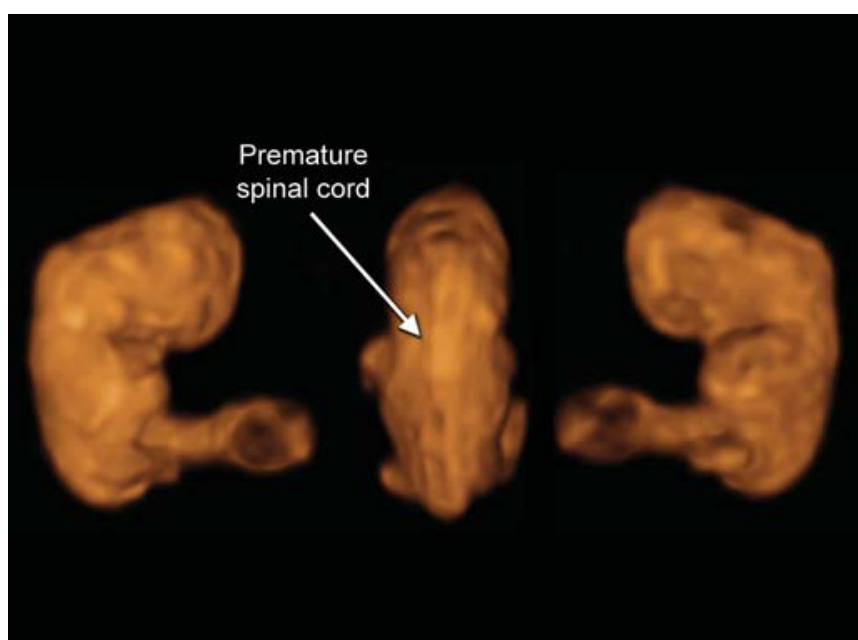

Fig. 3: 3D reconstructed image of the embryo (8 weeks of gestation). Normal 8-week embryo. Occipital view shows the premature spinal cord which is seen in the Figure 4 (right)

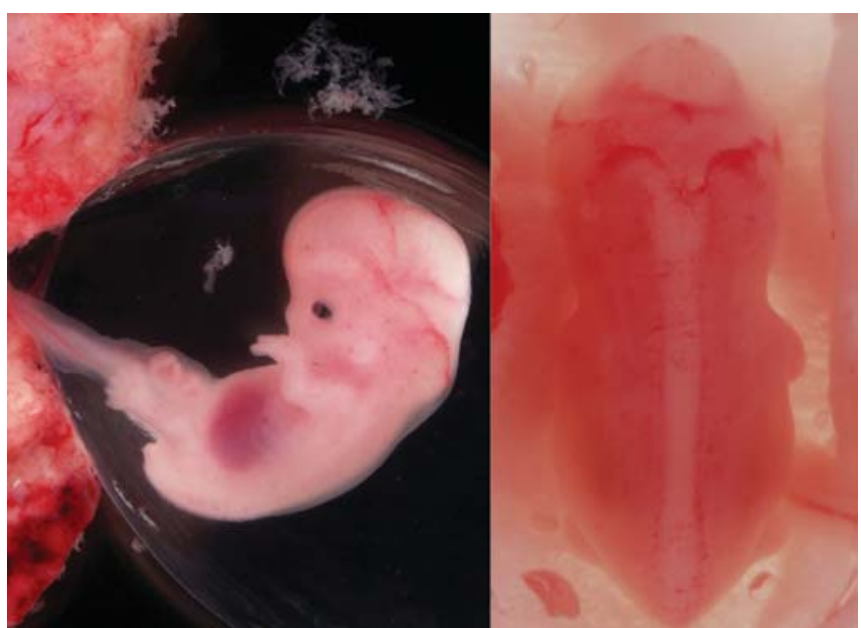

Fig. 4: Lateral and back view of aborted embryo at 8 weeks of gestation-(left) lateral view. Physiological umbilical hernia is seen(right) backside view. Premature spinal cord is seen. This photo was taken just after abortion before preserving in formalin

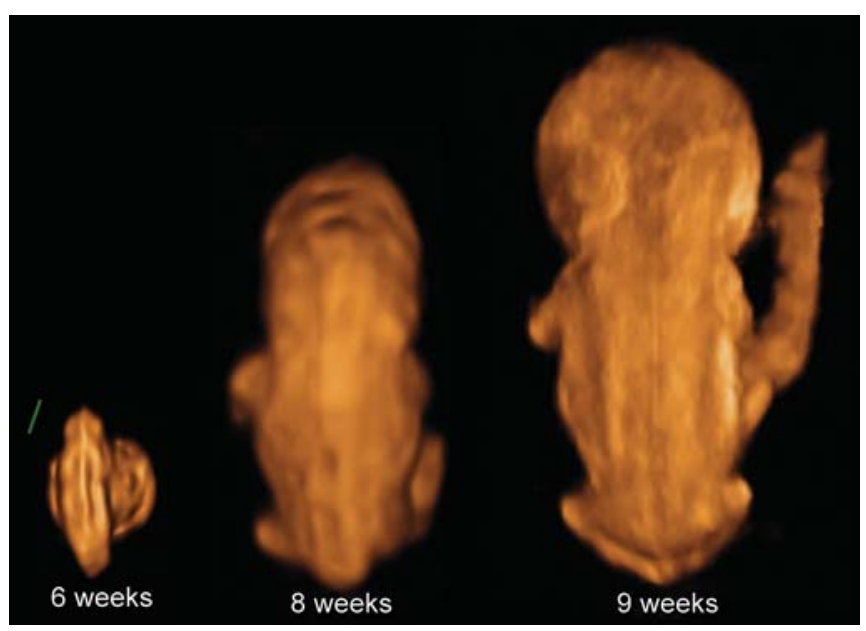

Fig. 5: 3D reconstructed image of the embryo (6 to 9 weeks of gestation). Embryonal sizes are 5.5, 18.3 and $26.3 \mathrm{~mm}$. At 9 weeks of gestation, the spinal cord is demonstrated as a thin line, compared with that at 8 weeks of gestation 

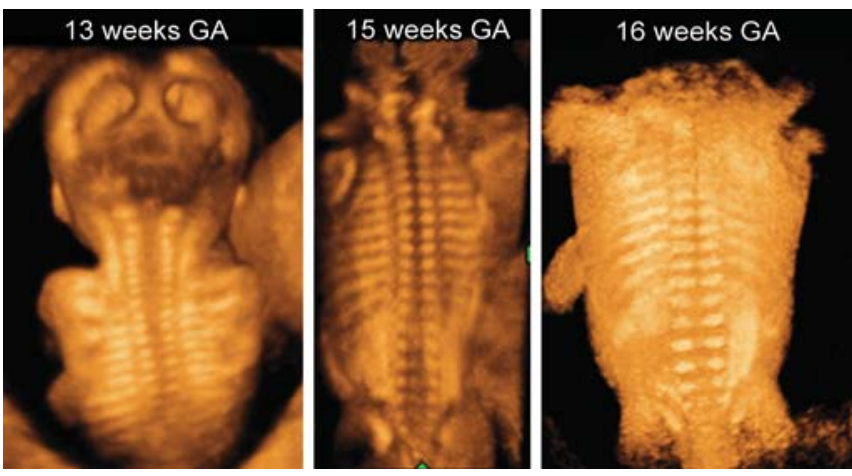

Fig. 6: 3D reconstructed image of fetal vertebral development between 13 and 16 weeks of gestation
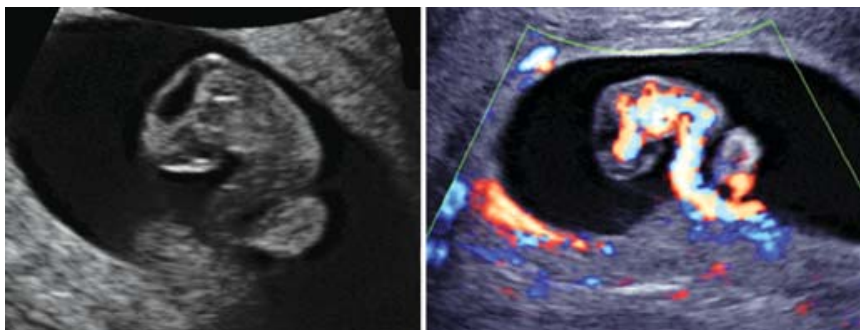

Fig. 7: Early vascular system at 9 weeks of gestation. (Left) 3D gray mode, (right) 3D power Doppler with surface appearance

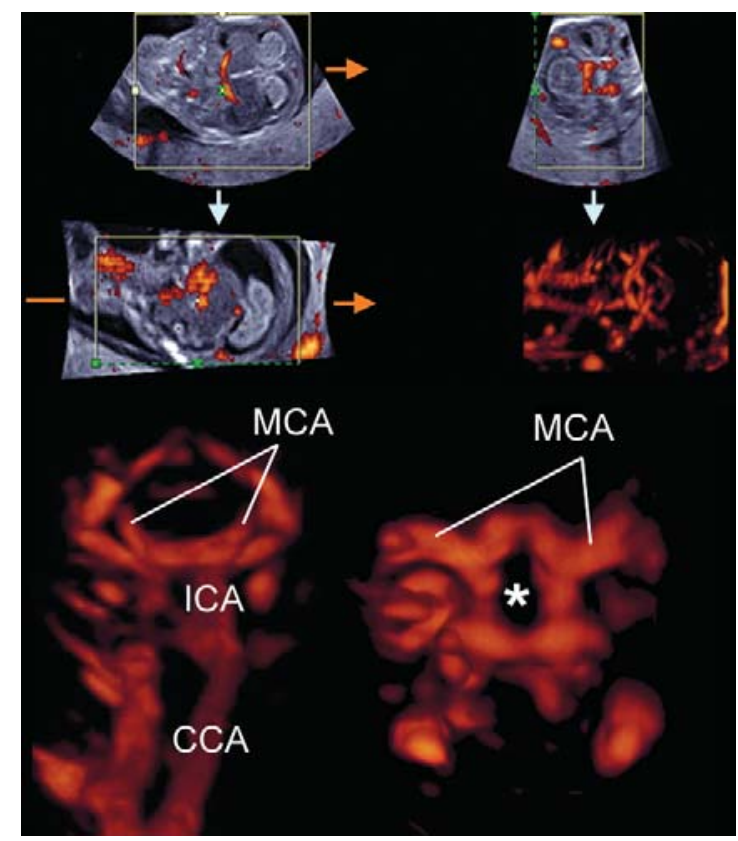

Fig. 8: Premature vascularity of normal 12-week brain. (Upper) Three orthogonal view of power Doppler image and 3D reconstructed image (front-back view of A plane). (Lower left) frontback image of common carotid arteries (CCA), internal carotid arteries (ICA) and brain basilar arteries. MCA: Middle cerebral artery. (Lower right) 3D image from fetal parietal direction. The circle of Willis (asterisk) is clearly visualized

in the embryonic brain. Figures 13 to 15 demonstrate fetal brain detailed morphology between the beginning of 8th and 10th weeks, and this can be accomplished through the use of three orthogonal planes and 'tomographic ul trasound imaging'. Serial examinations allow obtaining similar

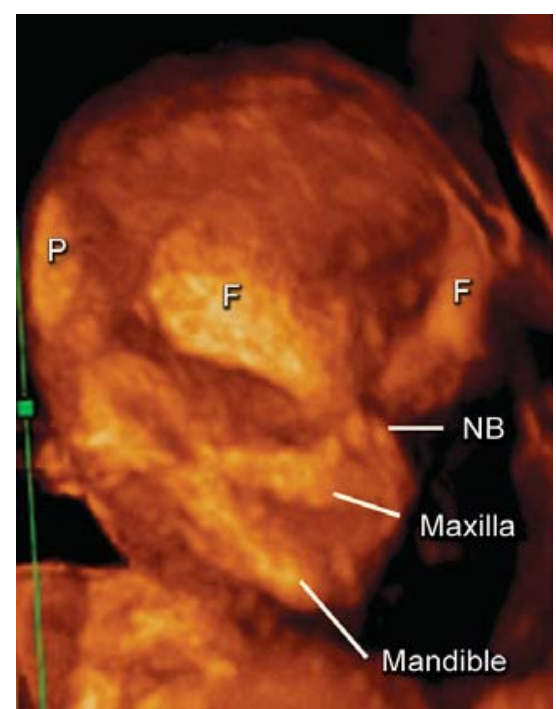

Fig. 9: 3D maximum mode image of normal craniofacial structure at 11 weeks of gestation. Premature bony structure of frontal bone $(F)$, parietal bone $(P)$, nasal bone (NB), maxilla and mandible are recognizable

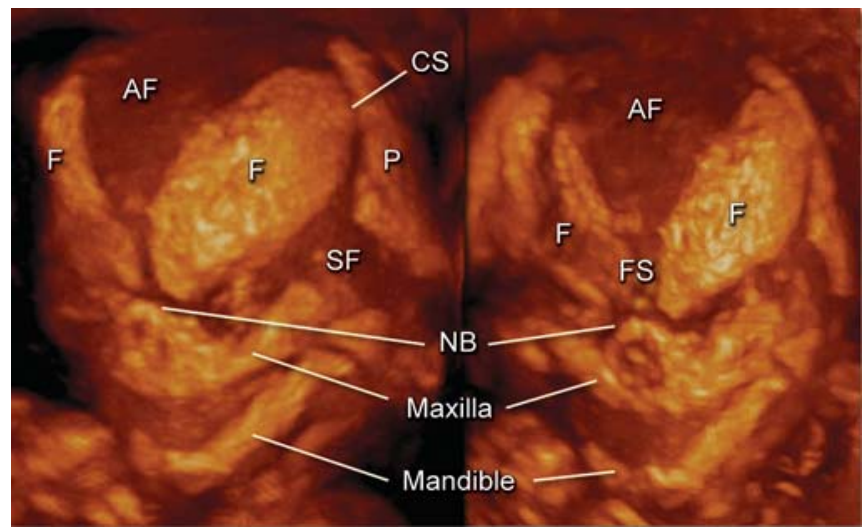

Fig. 10: 3D maximum mode image of normal craniofacial structure at 14 weeks of gestation (Left) oblique view. (Right) frontal view. Anterior fontanelle (AF), sphenoidal fontanelle (SF), frontal suture (FS), coronal suture (CS), nasal bone (NB), maxilla and mandible are gradually formed according to cranial bony development

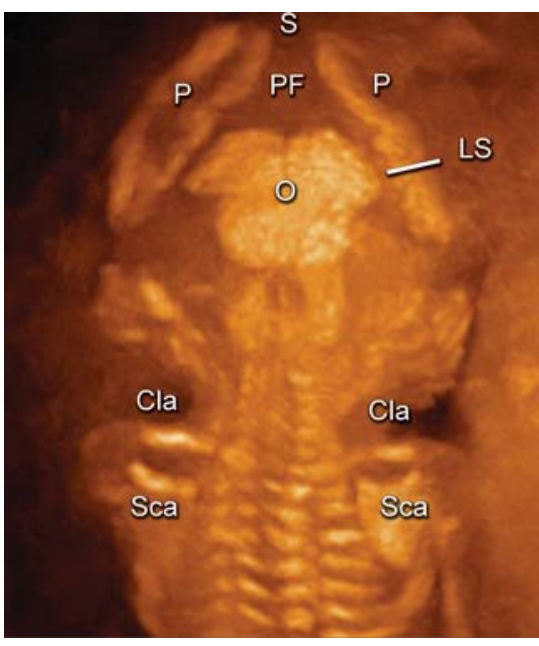

Fig. 11: 3D maximum mode image of occipital view at 13 weeks of gestation. Note the premature occipital bone appearance. Midline crack is demonstrated. S: Sagittal suture, P: Parietal bone, PF: Posterior fontanelle, O: Occipital bone, Cla: Clavicula; Sca: Scapula, LS: Lambdoid suture 


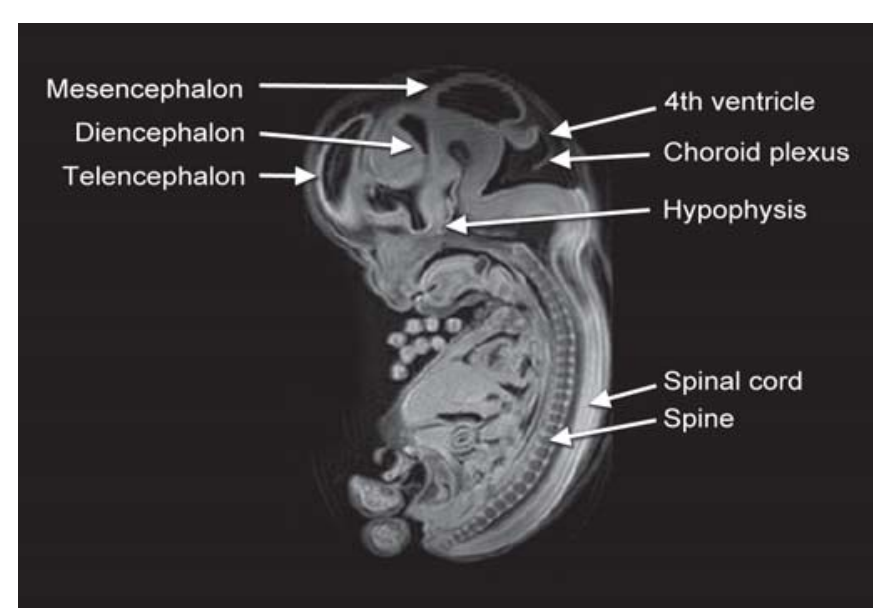

Fig. 12: Embryo structures visualized by magnetic resonance image (Carnegie stage 23)

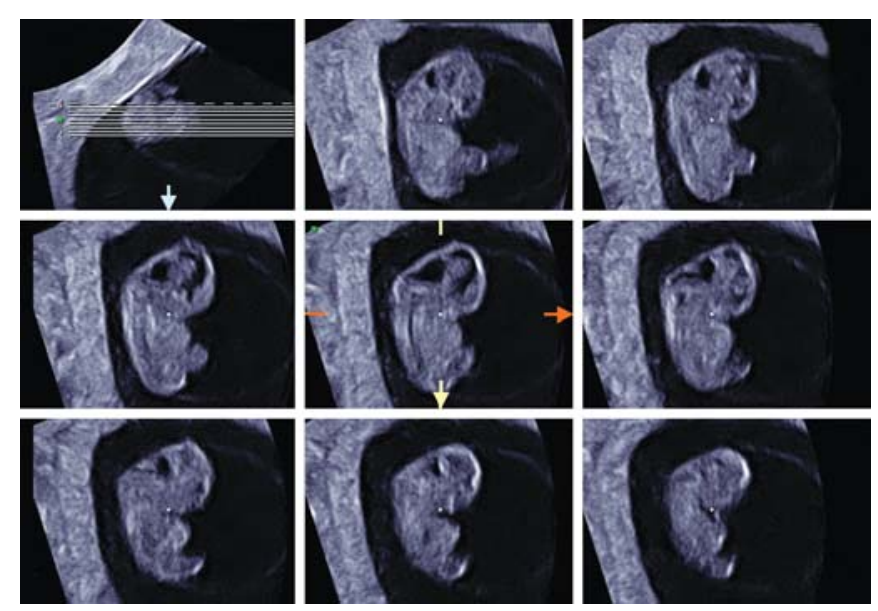

Fig. 13: Tomographic sagittal imaging of normal fetus at the beginning of 8 weeks of gestation

sections of the fetal brain at different stages of development. Therefore, it is possible to document the changes in CNS development between 8th and 12th weeks as demonstrated in Figure 16. Recent reports published on embryonal ventricular development from 6th or 7th weeks by use of 3D inversion-rendering mode, have made sonoembryology more sophisticated and objective. ${ }^{10,11}$ It is possible that by developing 3D neurosonoembryology imaging in utero, current fetal staging (which uses gestational age based on last menstrual period or CRL measurement) may change into a 'morphological staging system,' such as the Carnegie staging system, which has been central to embryology. ${ }^{4}$

Thoracoabdominal structures can also be imaged in the first trimester. For example, Figure 17 shows tomographic ultrasound imaging of fetal chest and abdomen at 13 weeks of gestation. Clear visualization of the lung-liver interface can be of value in the early diagnosis of thoracoabdominal abnormalities, such as a diaphragmatic hernia.
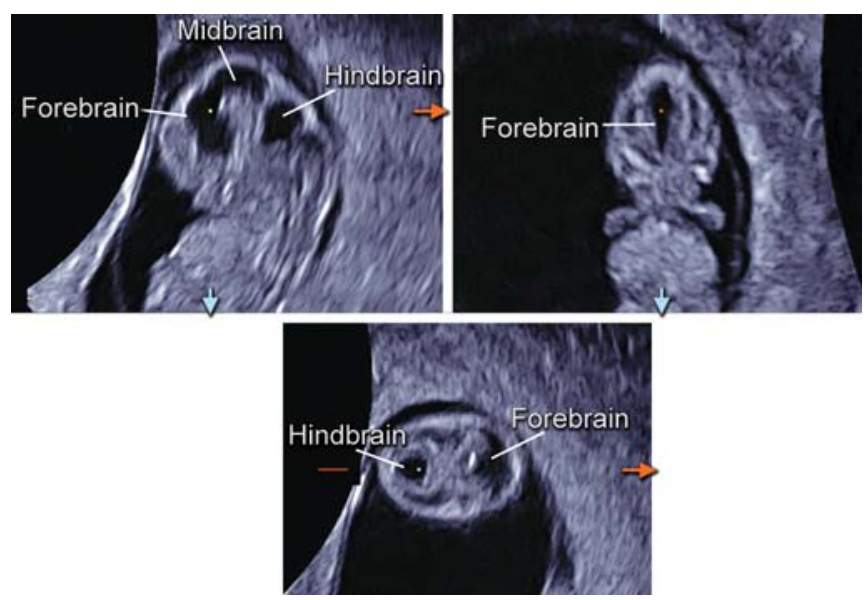

Fig. 14: Three orthogonal image of normal brain at the end of 8 weeks of gestation. The development of premature ventricular system is seen. Note the different appearance from the beginning of 8 weeks of gestation (Fig. 17)

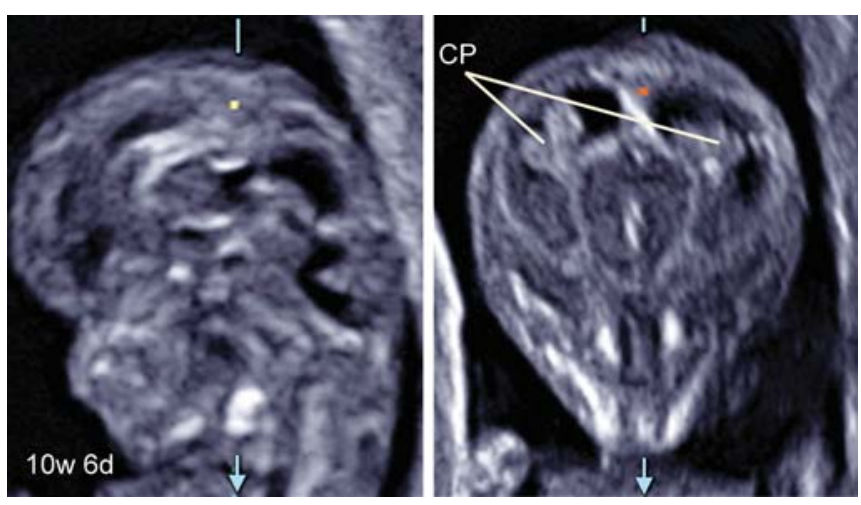

Fig. 15: Sagittal section and coronal sections of 10-week fetus. CP: Choroid plexus of the lateral ventricles
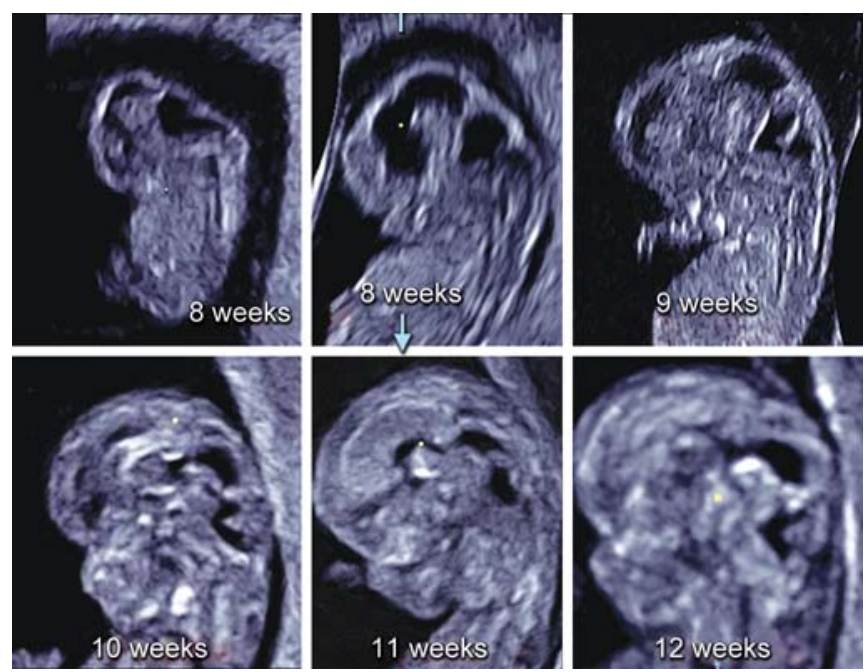

Fig. 16: Normal brain development by midsagittal 3D ultrasound section between 8 and 12 weeks of gestation

Fetal Abnormalities in the First Trimester

Yolk Sac

The yolk sac plays an important role in embryonal hemopoiesis and fetomaternal transportion of nutritive properties before establishment of fetoplacental circulation. 


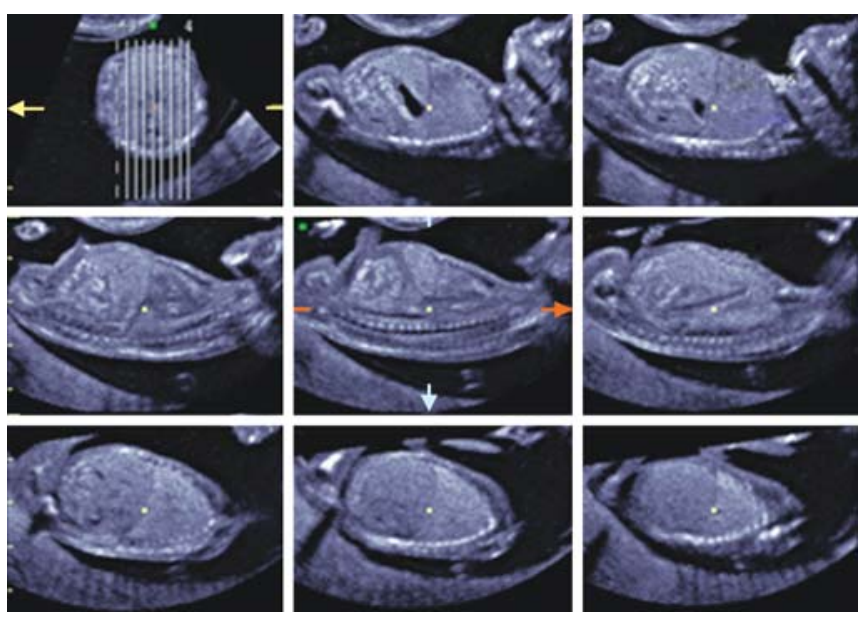

Fig. 17: Tomographic ultrasound imaging of normal thoracoabdominal structure at 13 weeks of gestation. Parallel sagittal sections are shown. Lung-liver border and intra-abdominal organs are clearly visualized
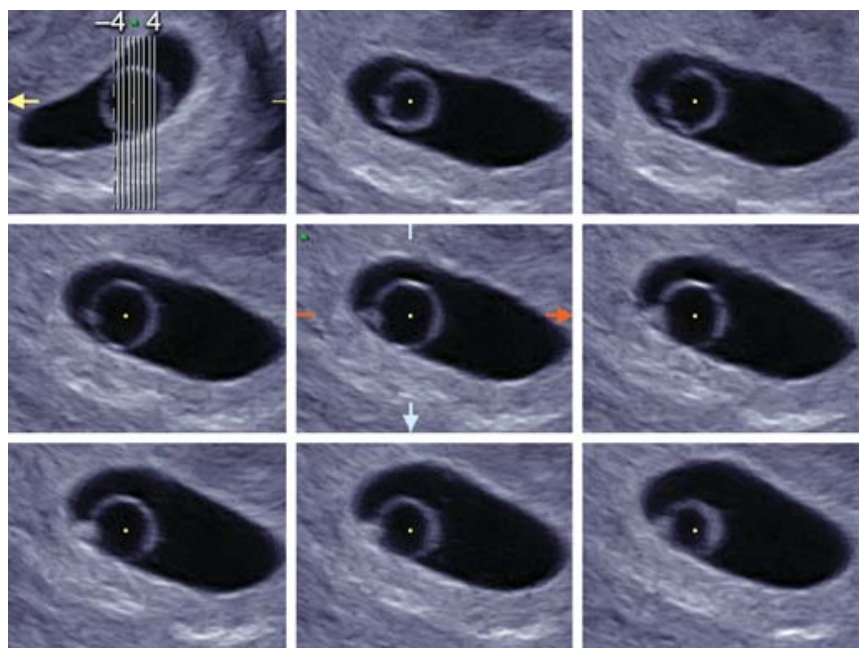

Fig. 18: Tomographic imaging of large yolk sac at 6 weeks of gestation. Large yolk sac with normal fetal heart beat was observed. Fetal demise was confirmed at 8 weeks. Villous chromosome exam resulted in $47, \mathrm{XY},+22$ )
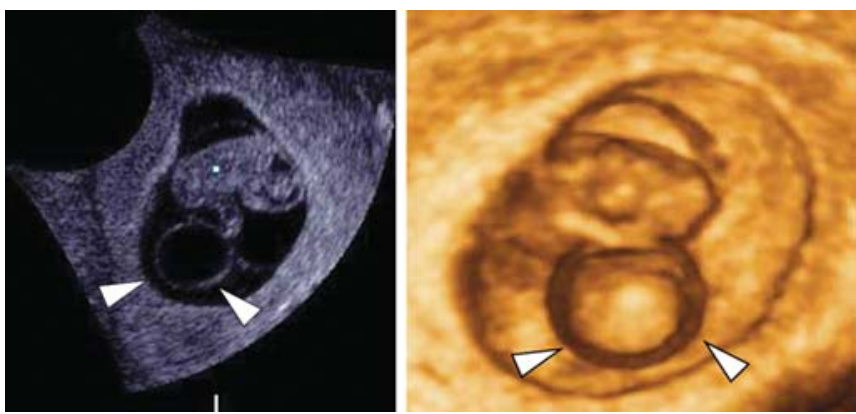

Fig. 19: Large yolk sac (arrow heads) at 8 weeks of gestation. (Left) two-dimensional sagittal section of the fetus. Normal appearance of 8-week fetus and amniotic membrane are visible, but large yolk sac with $12 \mathrm{~mm}$ of diameter is demonstrated. (Middle) regular fetal heart rate of $174 \mathrm{bpm}$ is confirmed. (Right) 3D image. Intrauterine fetal demise was confirmed 30 hours later. Villous chromosome exam resulted in doubled trisomy of $48, \mathrm{XY},+15,+21$

The primary yolk sac forms at around 3rd weeks of the menstrual age, then following the formation of the
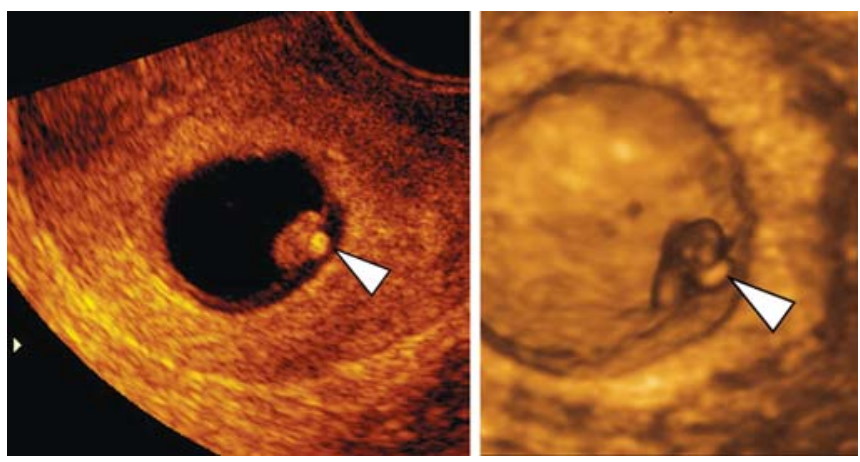

Fig. 20: High echogenic yolk sac (left) 2D ultrasound image of yolk sac (arrow head) at 9 weeks and 1 day. Small embryo compatible with 7-week embryo was visible with regular heart beats in the abnormally large amniotic sac. (Right) 3D ultrasound image. Intrauterine fetal demise was confirmed 3 days later and villous chromosome was trisomy 15

extraembryonic coelom, and the secondary yolk sac is formed. From the 6th weeks of gestation, it appears as a spherical and cystic structure covered by numerous superficial small vessels merging at the basis of the vitelline duct. This connects the yolk sac to the ventral part of the embryo, the gut and main blood circulation. During the 10th week of gestation, the yolk sac begins to degenerate and rapidly ceases to function. ${ }^{12}$

It has been reported that abnormal size and/or shape of yolk sac may be associated with ominous pregnant outcome. ${ }^{13} \mathrm{~L}$ arge yolk sac is defined more than two standard deviations above the mean, which indicates over $5.6 \mathrm{~mm}$ of diameter at less than 10 weeks menstrual age. ${ }^{13,14} \mathrm{~L}$ arge yolk sac is associated with chromosomal aberration of autosomal trisomy (Figs 18 and 19). Echogenic yolk sac (Fig. 20) is also related to adverse pregnant outcome with autosomal trisomy.

\section{Diagnosis of Congenital Anomalies in the First Trimester}

The prenatal diagnosis of congenital anomalies with ultrasound is based upon identification of a substantial departure of normal anatomy. This has been possible in the second and third trimesters of pregnancy, and this achievement has made the diagnosis of congenital anomalies one of the objectives of modern prenatal care. The definition of the 'normal anatomy' of the human embryo provides the basis for the identification of congenital anomalies at the earliest stages of human development. This goes beyond the mere identification of nuchal translucency, because it is now possible to identify anomalies even in the absence of an abnormal nuchal translucency. Therefore, the scope of prenatal diagnosis during embryonic life has been widened by sonoembryology with 3D ultrasound. ${ }^{4}$ 

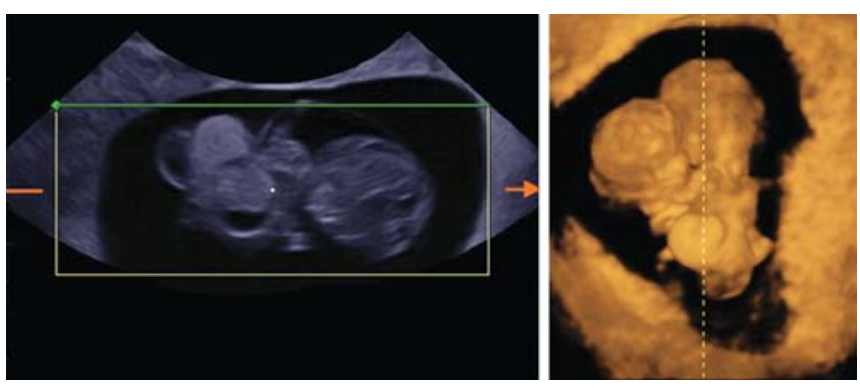

Fig. 21: Conjoined twins with limb-body wall complex at 9 weeks of gestation. Two heads and one body are obviously demonstrated. Liver and other abdominal organs were prolapsed

\section{Conjoined Twin}

Conjoined twins are defined as monochorionicmonoamniotic twins fused at any portion of their body as a result of an incomplete division of the embryonic disk after the 13th day of conception. Pathogenesis of the condition is considered as the result from failure of complete separation. Careful observation in the first trimester can reveal this condition from the early pregnancy. Figure 21 demonstrates conjoined twin with limb-body wall complex at 9 weeks of gestation. 3D ultrasound can objectively depict this rare abnormality.

\section{Central Nervous System (Cranium, Brain, Vertebra} and S pinal Cord) Anomalies

A crania, frequently found by early ultrasound scan, is characterized by a partial or complete absence of the cranium. The cranial shape and appearance vary, according to the extent of brain destruction. Figure 22 shows acrania complicated with cervical spina bifida, which is demonstrated by 3D-reconstructed imaging. Holoprosencephaly can be detectable by careful observation of the midline and choroid plexus appearance (Fig. 23). Occasionally, cephalocele is detectable as shown in Figure 24.

Spina bifida is the most common congenital spinal cord anomaly. It is often detected during the second and third trimesters. H owever, the fundamental basis for this anomaly is a failure of the neural tube to close during early embryonic age. M ost reports of the diagnosis of spina bifida in utero have occurred after 12 weeks of gestation. B laas et al ${ }^{15}$ reported an early diagnosis using $2 \mathrm{D}$ and $3 \mathrm{D}$ ultrasound before 10 weeks of gestation. Figure 25 shows the early diagnosis of spina bifida in a case of OEIS complex (omphalocele, bladder exstrophy, imperforate anus, spina bifida) at 9 weeks of gestation. Iniencephaly is a rare neural tube defect that combines extreme retroflexion (backward bending) of the head with severe defects of the spine, associated with acrania, anencephaly and encephalocele.
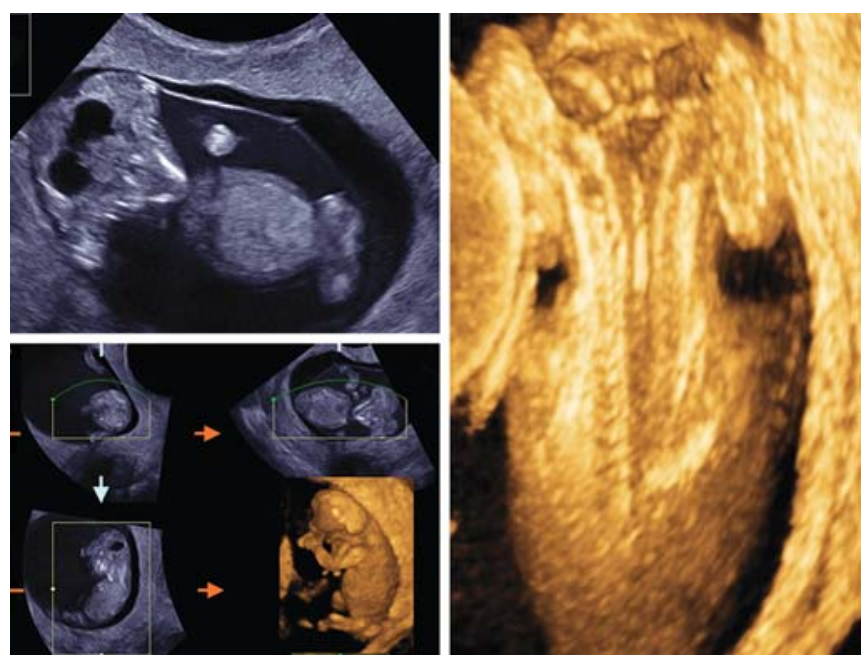

Fig. 22: Acrania with cervical spina bifida (craniorachischisis) at 11 weeks of gestation. Left upper: 2D image. Note the amniotic fluid is more turbid than chorioamniotic cavity due to floating nerve tissue from destroyed brain. Left lower; three orthogonal view and reconstructed image. Right: 3D-reconstructed image of cerebrospinal region. This fetus is complicated with acrania and cervical spina bifida, so-called craniorachischisis
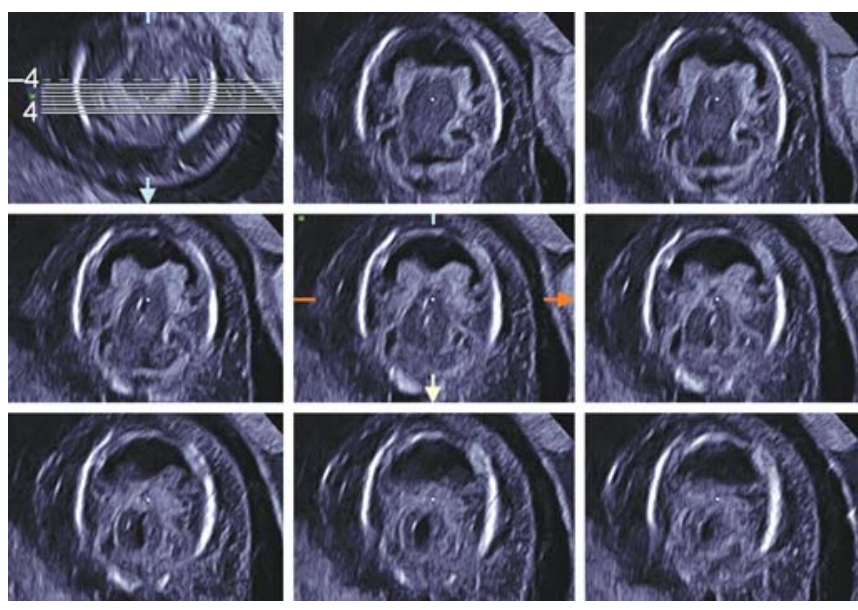

Fig. 23: Holoprosencephaly at 12 weeks of gestation. Tomographic ultrasound imaging shows a single ventricle due to nonseparated hemispheres
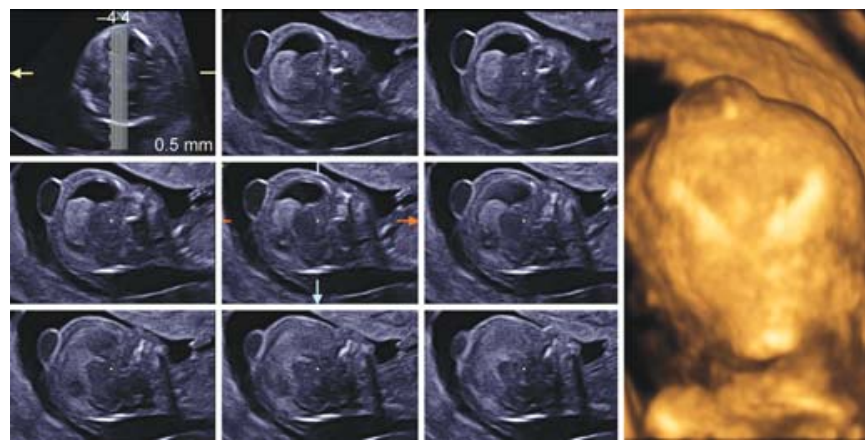

Fig. 24: Cephalocele at 12 weeks of gestation. Cephalocele containing translucent fluid is seen on the parietal right side of the head. This cyst disappeared 2 weeks later

The prognosis for those with iniencephaly is extremely poor. Early detection of iniencephaly is possible (Fig. 26). 


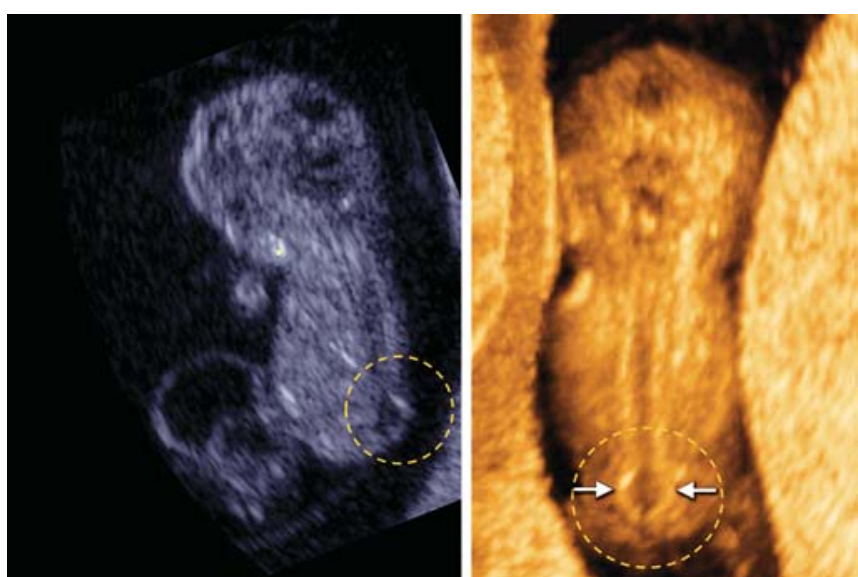

Fig. 25: Spina bifida at 9 weeks of gestation. Left: 2D sagittal image. Cystic formation was seen (white circle) at lumber part. Right: 3D image of neural tube. Clear dilatation of the neural tube is demonstrated (arrows)
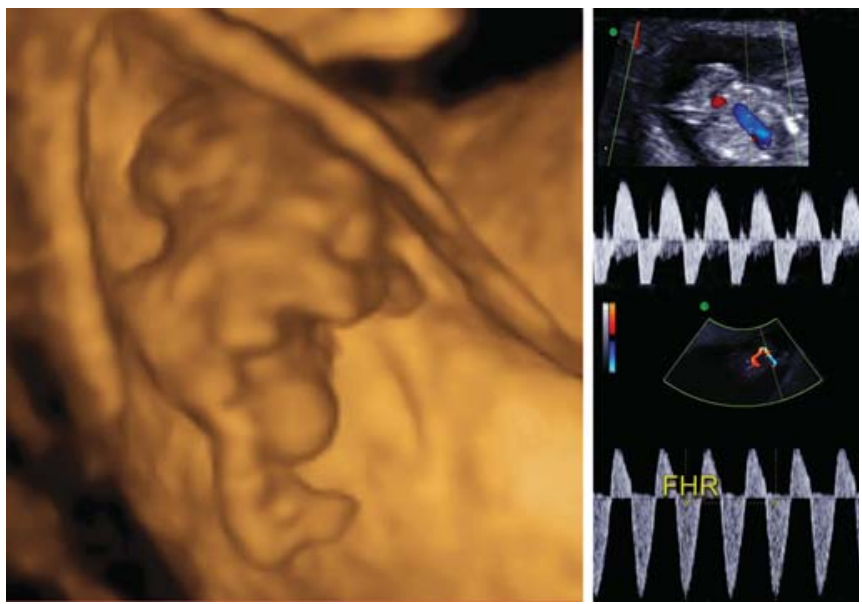

Fig. 26: Iniencephaly at 12 weeks of gestation. Left: 3D reconstructed image. Acrania, short body with dorsoflexion are well demonstrated. Right: This fetus had reverse flows of descending aorta (right upper) and umbilical artery (right lower) and intrauterine fetal demise was confirmed 1 week later
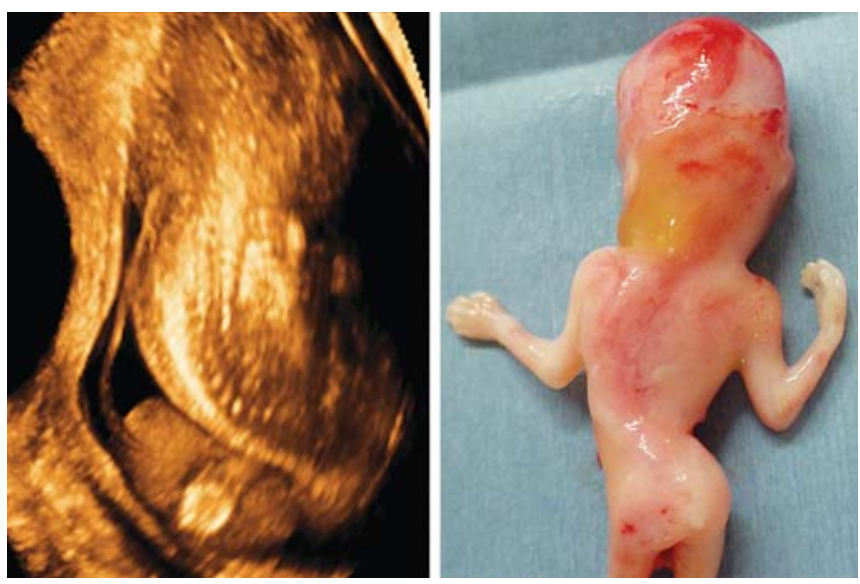

Fig. 27: Severe scoliosis at 12 weeks of gestation. Left: 3D image of fetal back. Severe scoliosis is demonstrated. Right: Back view of aborted fetus. Fetal karyotype was normal

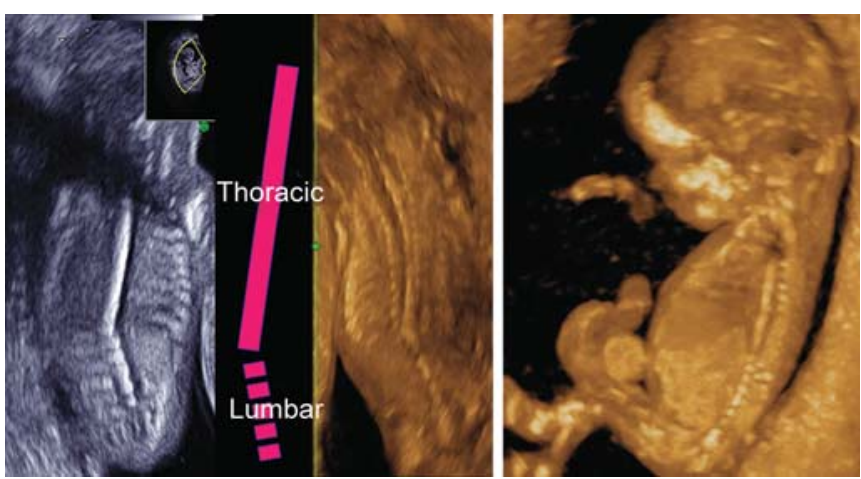

Fig. 28: Fused thoracic vertebral body with scoliosis at 13 weeks of gestation. Left: 2D sagittal image. Thoracic vertebral body is completely fused, while lumber vertebral bodies are apart. Middle: 3D maximum mode of dorsal view. Right: 3D maximum mode of lateral view
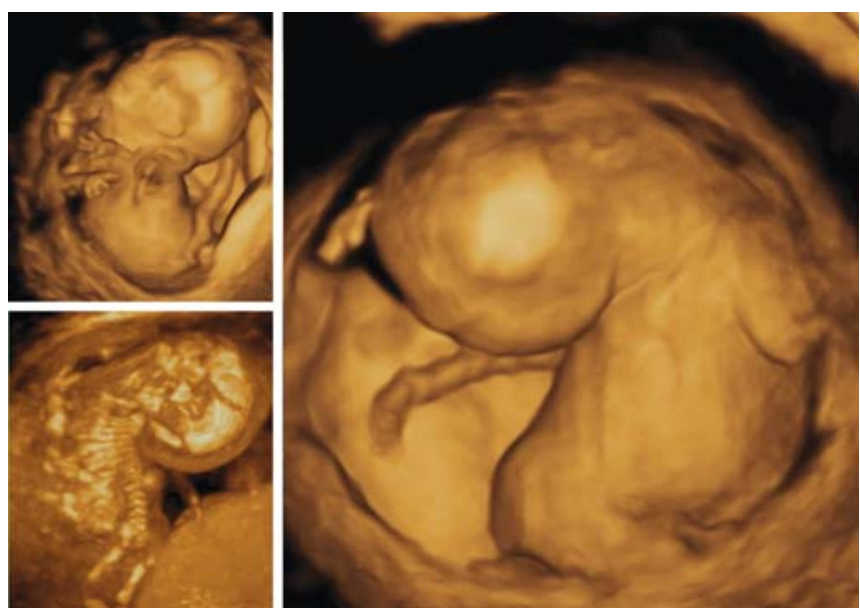

Fig. 29: Extreme hyperdorsiflexion seen in a case of trisomy 21 at 14 weeks of gestation. Left upper and right: 3D-reconstructed oblique anterior and lateral views of the fetus. Left lower: 3D maximum mode demonstrating bony structure

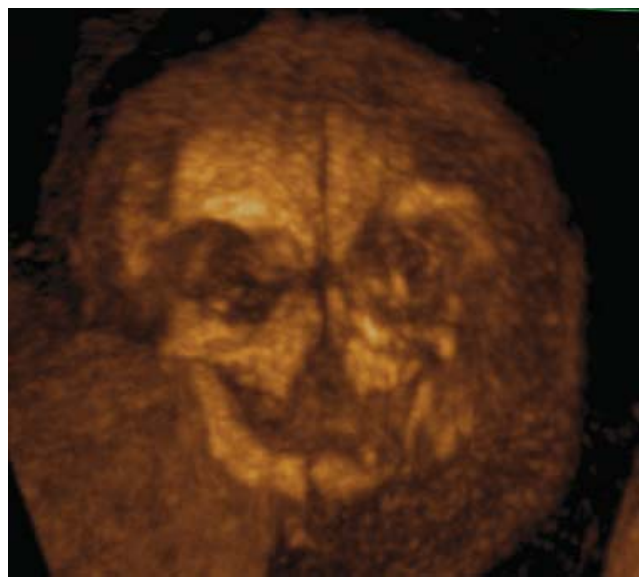

Fig. 30: Cleft palate associated with holoprosencephaly. 3D maximum mode image demonstrates midline large cleft of maxilla 
Scoliosis is often associated with limb-body wall complex (Fig. 27) and rarely scoliosis is associated with early vertebral fusion as shown in Figure 28. Extreme hyperdorsiflexion (backward bending) is a rare finding with unknown clinical significance. Figure 29 demonstrates extreme hyperdorsiflexion seen in a case of trisomy 21.

\section{Facial A bnormalities}

A facial anomaly can be associated with a CNS anomaly (e.g. holoprosencephaly as shown in Figures 30 and 31), be an isolated finding, or part of a syndrome. Detection of the presence or absence of a nasal bone has been found to be of value in the assessment of aneuploidy in the first trimester of pregnancy (risk assessment for trisomy 21). ${ }^{16-20}$ Cicero et al ${ }^{20}$ reported that the nasal bone was absent in $113(0.6 \%)$ of the 20,165 chromosomally or phenotypically normal fetuses and in $87(62.1 \%)$ of the 140 fetuses with trisomy 21. 3D sonography allows a midsagittal section of the fetal face to be obtained by utilizing the three orthogonal planes, and avoids the pitfall of obtaining a parasagittal view, which could lead to false-negative results. Tomographic ultrasound imaging also allows demonstration of facial midline structures in detail, by examining close parallel sections (Fig. 32). It is important to be aware that the quality of the orthogonal planes or tomographic imaging is strongly dependent upon the original plane of acquisition. Rembouskos et al ${ }^{21}$ described that routine application of $3 \mathrm{D}$ scanning for the nasal bone in screening for trisomy 21 is likely to be associated with a very high false-positive rate due to the possible limits of 3D technology. Benoit and Chaoui ${ }^{22}$ described the diagnosis of bilateral or unilateral absence or hypoplasia of nasal bones in second trimester screening for D own syndrome by using 3D sonography with maximal mode rendering. Figure 33 shows the midsagittal section of fetal face and craniofacial bony reconstructed image of normal fetus and trisomy 21 fetuses in the first trimester.

A short maxillary length has been associated with trisomy $21 .{ }^{23} \mathrm{M}$ icrognathia can be detected as an isolated structural anomaly, as one of the features of a chromosomal abnormality, or a syndrome. ${ }^{24}$ Congenital micrognathia and lowest ears are frequently detected together as shown in Figure 34, in cases with chromosomal aberrations and other syndromic diseases, because mandibula and ears arises from the first pharyngeal (branchial) arch. A ssessment of the facial features, chin development, and mandibular size by $3 \mathrm{D}$ ultrasound in the second and third trimesters has been reported. ${ }^{25}$ By using the surface mode and maximum mode (Fig. 35), the fetal profile and facial bone structure in normal and abnormal fetuses can be described in the first trimester.
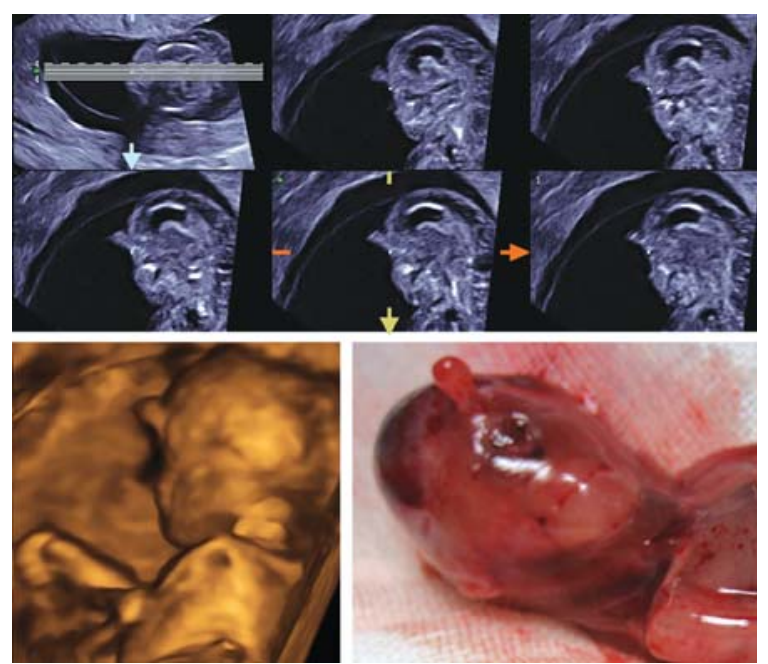

Fig. 31: Proboscis associated with holoprosencephaly at 12 weeks of gestation. Upper: Tomographic facial sagittal imaging of holoprosencephalic fetus. Lower left: 3D-reconstructed image of fetal face, lateral view. Lower right: Macroscopic picture after termination of pregnancy

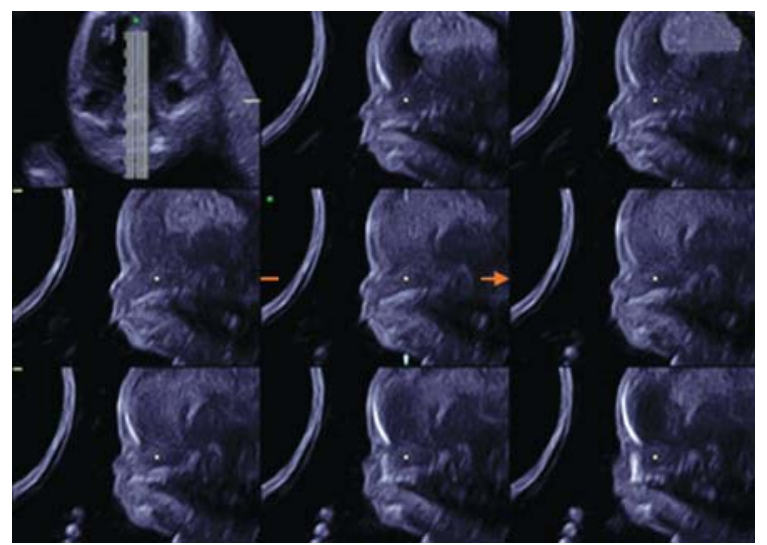

Fig. 32: Tomographic ultrasound image of fetal profile with hypoplastic nasal bone at the end of 13 weeks of gestation. Thinly sliced parallel cutting section of midsagittal plane shows fetal profile in detail and hypoplastic nasal bone. Trisomy 21 was confirmed by chorionic villus sampling
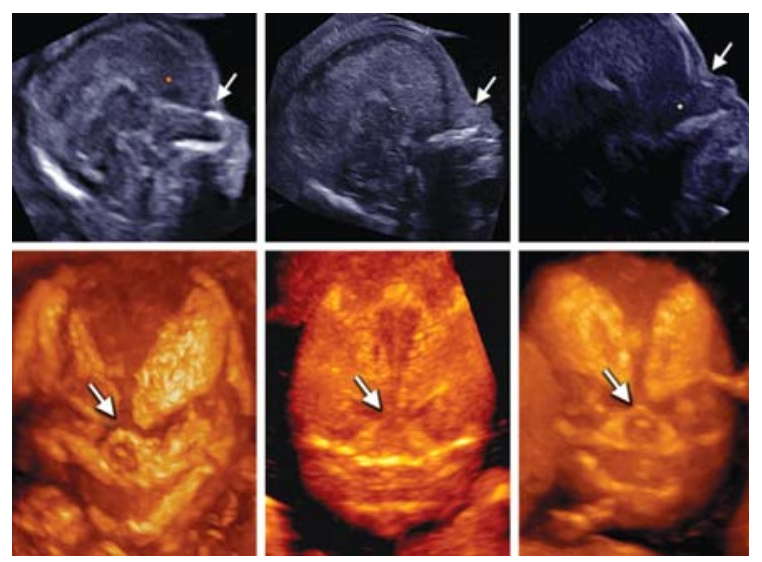

Fig. 33: Midsagittal 2D image of fetal profile and craniofacial bony reconstructed image of normal fetus (Left) and trisomy 21 fetuses (middle and right) at 13 to 14 weeks of gestation. (Left) normal fetus. Nasal bone is clearly visualized in both two-dimensional and 3D images (arrows). (Middle) Nasal bone defect in a case of trisomy 21. Nasal bone is completely missing in both $2 \mathrm{D}$ and 3D. (Right) Nasal bone hypoplasia in a case of trisomy 21 . Small nasal bone is visualized in both 2D and 3D 

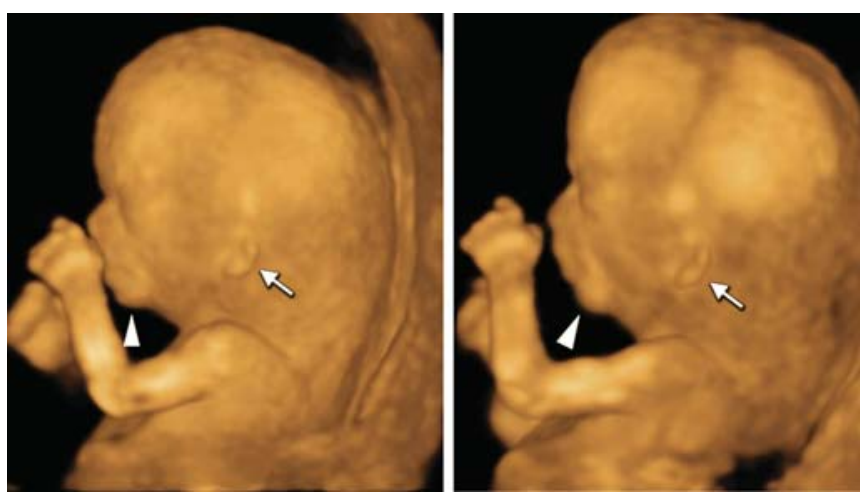

Fig. 34: Micrognathia and low-set ears at 13 weeks of gestation. Both images are from the same fetus. Micrognathia (arrowheads) and lowest ears (arrows) are clearly demonstrated by 3D-reconstructed images
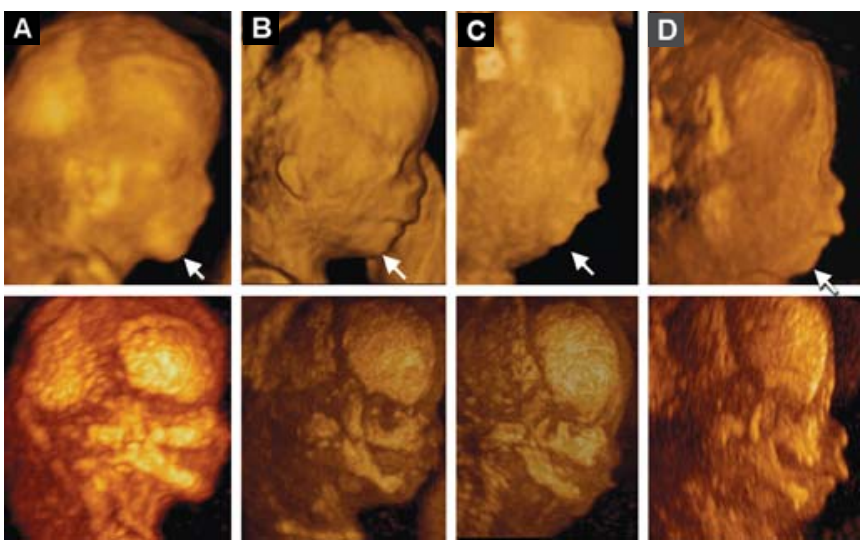

Fig. 35: Fetal profile and facial bone development in normal fetus (A) and abnormal fetuses $(B, C, D)$ at 12 to 13 weeks of gestation. A: Normal fetus, B: Trisomy 21 fetus, C: Trisomy 18 fetus, D: Mild micrognathia with normal chromosome. Lateral views of fetal profile (upper figures) show the difference of chin-angle. Maximum mode images (lower figures) indicate the hypoplastic maxilla and mandible in $B, C, D$
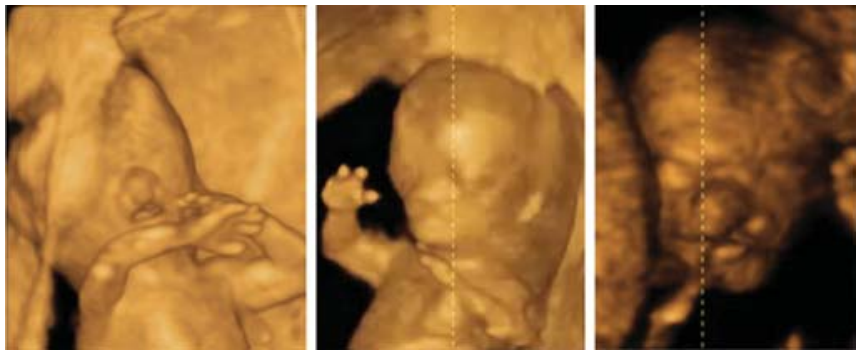

Fig. 36: Bilateral and unilateral cleft lip seen at 12 weeks of gestation. Left and middle: 3D-reconstructed images of bilateral cleft lip seen in cases of trisomy 18 (left) and trisomy 21 (middle). Right: 3D-reconstructed image of unilateral cleft lip seen as a single finding

Cleft lip and palate is usually demonstrated and diagnosed in the second and third trimesters. However, recent advances of the transvaginal 3D ultrasound have provided accurate and informative diagnostic images of cleft lip with orientation of left-sided, right-sided or bilateral cl eft lip (Figs 36 and 37). Furthermore, the palate is still created
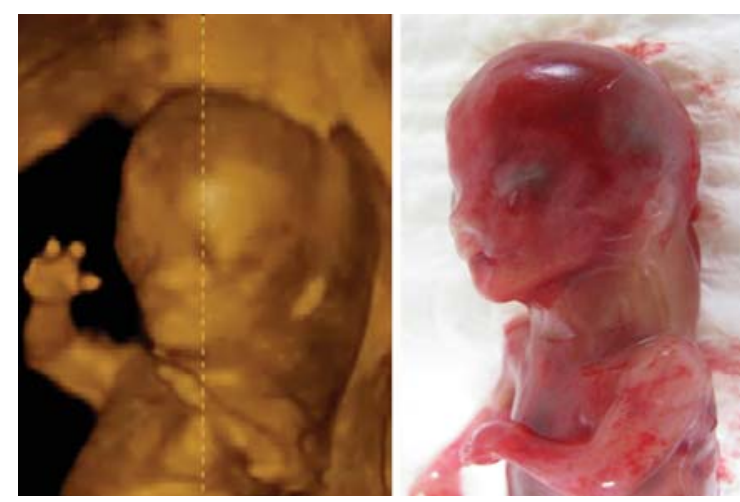

Fig. 37: Left-sided cleft lip seen at 12 weeks of gestation Left: 3D-reconstructed images of bilateral cleft lip seen in cases of trisomy 21. Right: Macroscopic picture of aborted fetus
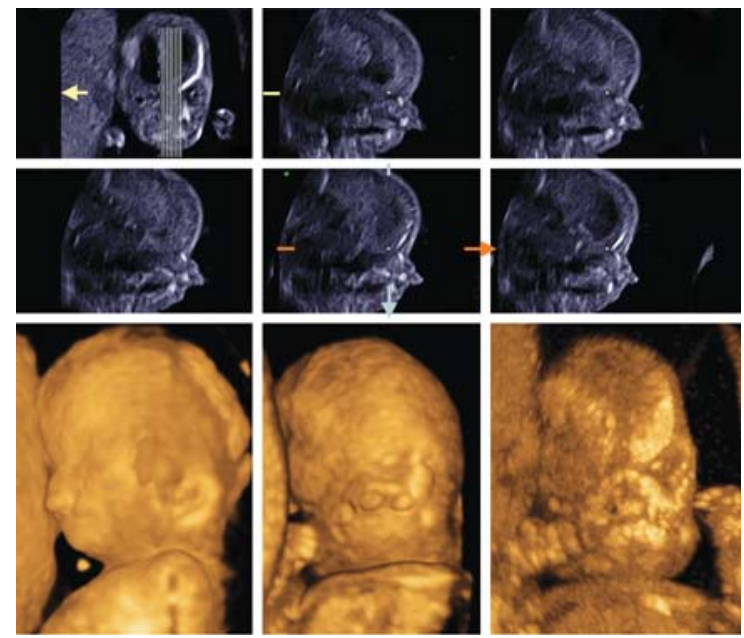

Fig. 38: Bilateral cleft lip and palate at 13 weeks of gestation. Upper: Tomographic sagittal facial imaging of the normal-karyotype anomalous fetus. Lower: 3D-reconstructed images. Oblique (left), frontal (middle) and maximum-mode frontal (right) views. Maximum image shows bilateral cleft of maxillary bone

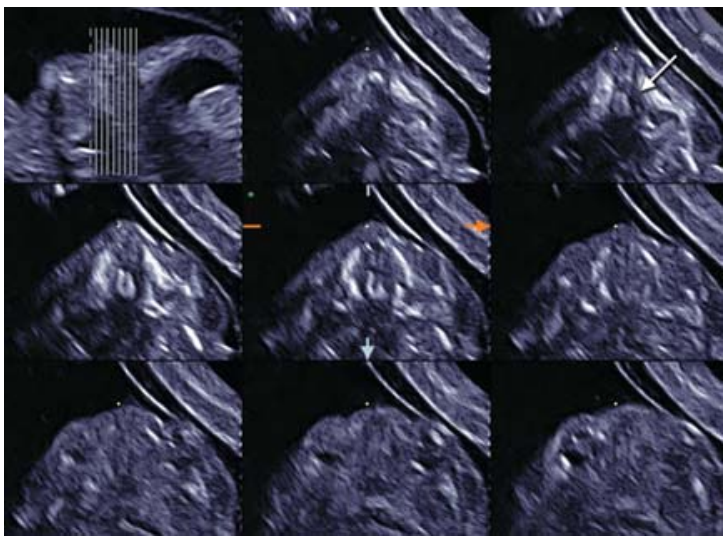

Fig. 39: Tomographic ultrasound imaging of cleft plate at 12 weeks of gestation. Unilateral cleft palate is demonstrated (arrow)

during pregnancy, but 3D reconstructed image can demonstrate cleft palate as shown in Figures 30 and 38. Up-to-date tomographic ultrasound imaging can provide the precise demonstration of pal ate shown in Figure 39 and the possibility of early diagnosis of cleft palate. 

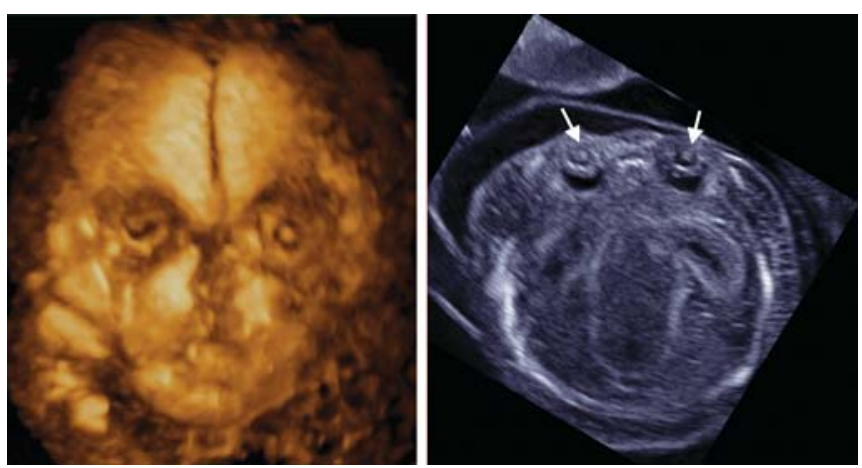

Fig. 40: Congenital cataract at 14 weeks of gestation. Bilateral congenital cataract with microphthalmia is demonstrated as lens opacity (arrows) in 3D (left) and 2D (right) images

Eyeballs and lenses are detectable by ultrasound from the late first trimester. Cataract is defined by the presence of any lens opacity. The incidence of congenital cataract ranges from 1 to 6 newborn infants out of 10,000 births. $^{26}$ Cataract development is strongly linked to the embryonic ocular development. The lens differentiates from the surface ectoderm before the 6th week of gestation, explaining the absence of cataract in case of late first trimester fetal infection. ${ }^{27,28} \mathrm{~A}$ genetic cause is responsible for $30 \%$ of unilateral cataracts and $50 \%$ of bilateral cataracts. Prenatal diagnosis of fetal cataract was reported in the late second and third pregnancies. ${ }^{29-33}$ Figure 40 shows fetal bilateral cataract with microphthalmia as early as 14 weeks of gestation.

\section{Limb Abnormalities}

Limb abnormalities can occur as isolated findings or as one component of a syndrome or sequence. However, only $5 \%$ of congenital hand anomalies occur as part of a recognized syndrome. ${ }^{34}$ Overlapping fingers, wrist contracture (Fig. 41) and forearm deformities are often associated with a
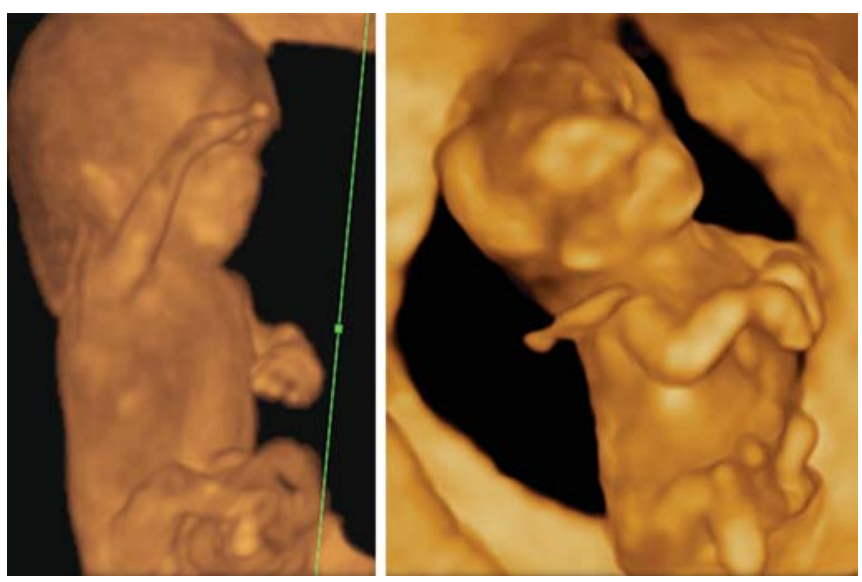

Fig. 41: Mild-to-moderate wrist contracture seen in cases of trisomy 18 at 12 to 13 weeks of gestation. Left: Mild wrist contracture is seen. Right: Moderate wrist contracture is seen. Trisomy 18 was confirmed by chorionic villi sampling

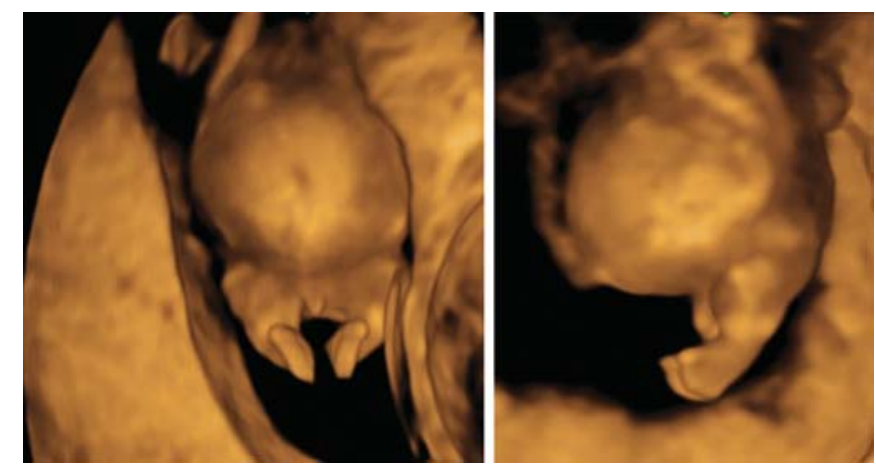

Fig. 42: Short limb abnormality at 13 weeks of gestation. Short lower extremities with large abdomen is clearly demonstrated in the frontal (left) and lateral (right) views
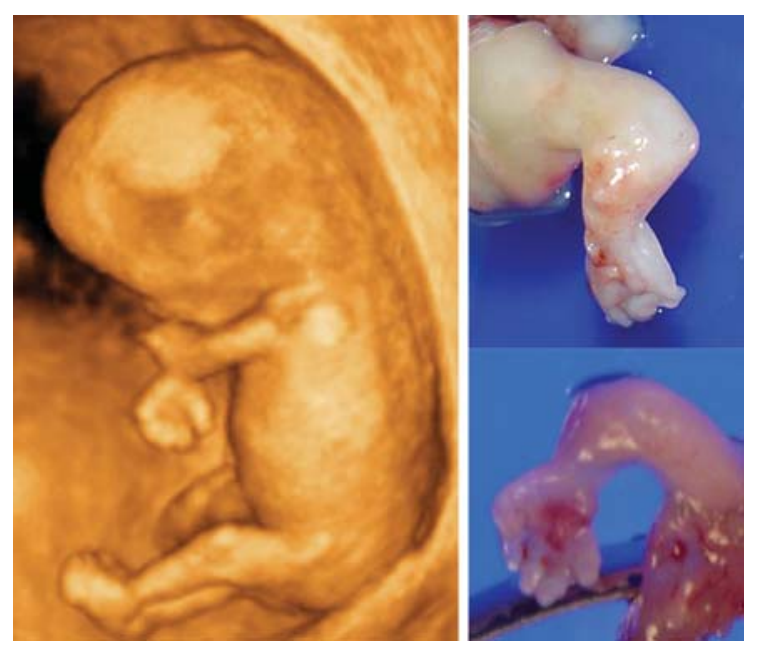

Fig. 43: Upper limb abnormality at 11 weeks of gestation. 3D ultrasound revealed contracted elbow joint abnormality. Right figures show macroscopic appearance of upper limbs of aborted fetus

chromosomal abnormality such as trisomy 18. M ost skeletal anomalies are recognizable in the second trimester. However, several reports on congenital skeletal abnormalities (such as sirenomelia and others) in the first trimester have been documented. ${ }^{35-39}$ Short limb abnormality of achondrogenesis in the first trimester was shown in Figure 42. Figure 43 shows an 11-week fetus on 3D sonography with skeletal dysplasia of the bilateral upper extremities and normal lower extremities. Clubfoot as shown in Figure 44 is not as common as clubhands in the first trimester. Finger abnormalities, such as polydactyly, oligodactyly and syndactyly, are detectable from the late first trimester. In Figure 45, polydactyly and syndactyly at 14 weeks in cases of holoprosencephaly are well demonstrated by 3D ultrasound.

\section{Thoracoabdominal Abnormalities}

Congenital diaphragmatic hernia ( $C D H$ ) occurs in 1 of every 2000 to 4000 live births and accounts for $8 \%$ of all major congenital anomalies. ${ }^{40}$ There are three types of $\mathrm{CDH}$ : 

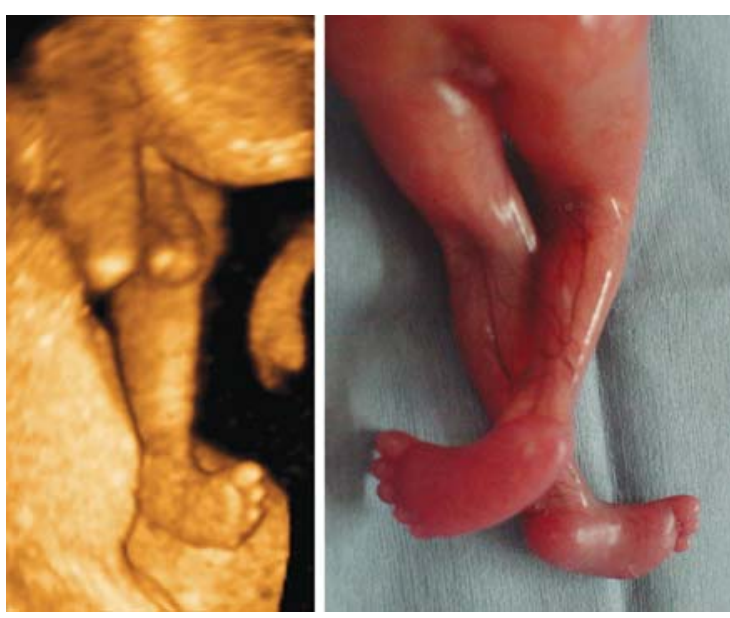

Fig. 44: Fetal clubfoot at 13 weeks of gestation. Left: 3D image of fetal leg. Right: Legs of aborted fetus. This case was associated with chromosomal aberration
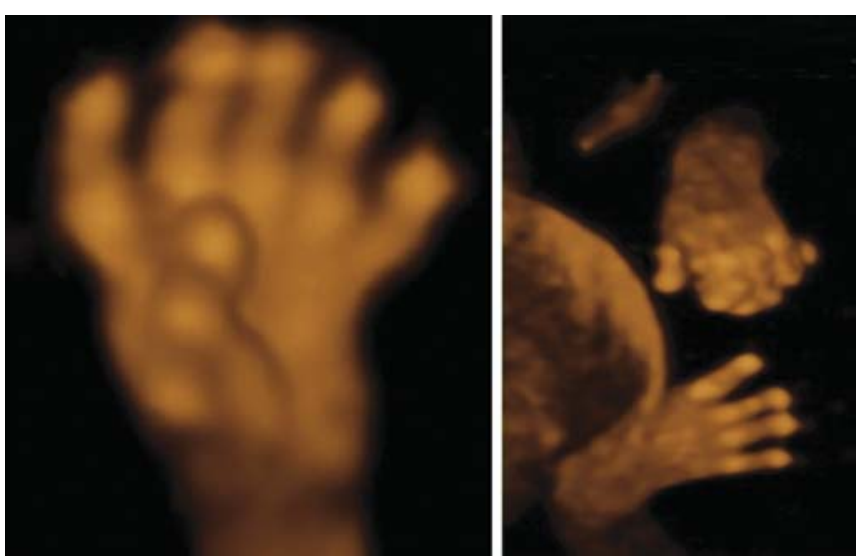

Fig. 45: Polydactyly and syndactyly at 14 weeks of gestation. 3D-reconstructed ultrasound images clearly depicted bilateral polydactyly (left) and left poly-/syndactyly (right). Both cases were associated with holoprosencephaly

posterolateral or Bochdalek hernia (occurring at approximately 6 weeks gestation), the anterior M orgagni hernia and a hiatus hernia. The left-sided Bochdalek hernia occurs in approximately $90 \%$ of cases. Left-sided hernias allow herniation of both small and large bowels as well as intra-abdominal solid organs into the thoracic cavity. Early diagnosis of $\mathrm{CDH}$ in the first trimester has been reported. ${ }^{41}$ Figure 46 shows the thoracoabdominal area of a fetus with a congenital diaphragmatic defect where the lung-liver borderline acutely changes its angle from 13 to 15 weeks, due to progressive liver upward movement into the chest. Early diagnosis of this defect is important. ${ }^{41}$

Omphalocele is often seen from the first trimester. Physiological umbilical hernia is usually observed around 8 to 10 weeks of gestation; however, umbilical hernia seen after the beginning of 12 weeks is definitely pathological (Fig. 47). Ectopic abdominal organs outside of amniotic cavity is often associated with short umbilical cord,
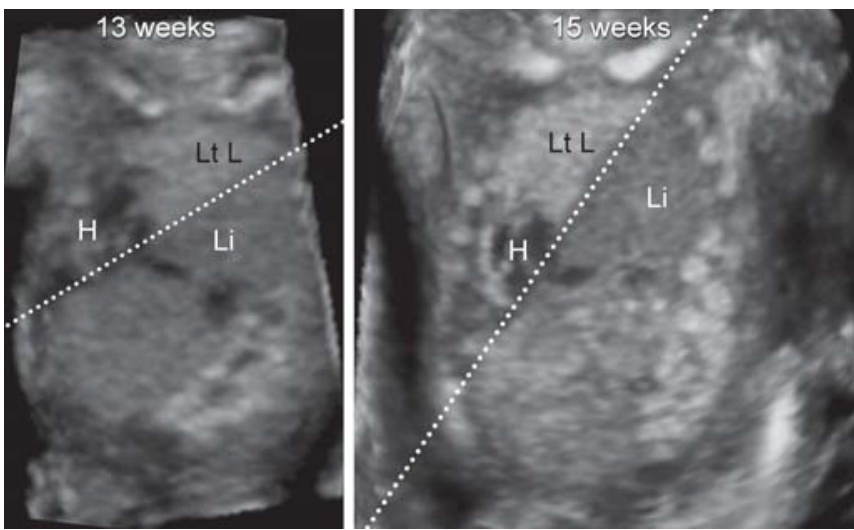

Fig. 46: Congenital diaphragmatic defect at 13 and 15 weeks of gestation. Referral case due to nuchal translucency of $3 \mathrm{~mm}$ at 11 weeks of gestation. (Left) frontal view at 13 weeks. Dextrocardia $(\mathrm{H})$, liver-up ( $\mathrm{Li})$ and oppressed left lung $(\mathrm{Lt} L)$ are demonstrated. (Right) frontal view at 15 weeks. The line of lung-liver border indicates acute angle changing in a short period due to progressive liver up
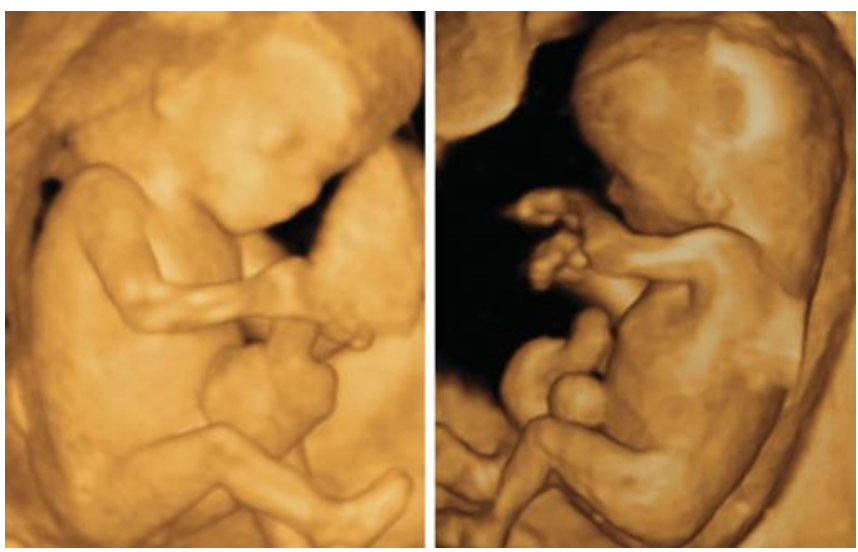

Fig. 47: Omphalocele at 12 and 13 weeks of gestation. 3D-reconstructed ultrasound images clearly demonstrates omphalocele. Trisomy 18 was confirmed by chorionic villi sampling in both cases

abnormal limbs and this condition is called as short umbilical cord complex, limb-body wall complex or body-stalk anomaly as shown in Figures 48 and 49, different from amniotic band syndrome.

\section{Urinary Tract Abnormality}

Bladder extrophy (Fig. 50) is a rare abnormality, which may be associated with cloaca malformation or the OEIS (omphalocele, bladder extrophy, imperforate anus, spine defect) complex. Prune-B elly syndrome (Fig. 51) describes the triad of dilation of the urinary tract, a deficiency of the abdominal wall musculature, and failure of testicular descent. Hydronephrosis is the most common pathologic finding in the urinary tract on prenatal screening by ultrasonography. Fetal obstructive uropathy has become detectable earlier and fetal therapy of vesicoamniotic shunting (VAS) is the accepted procedure in well-defined cases. It has been reported that the long-term outcomes 

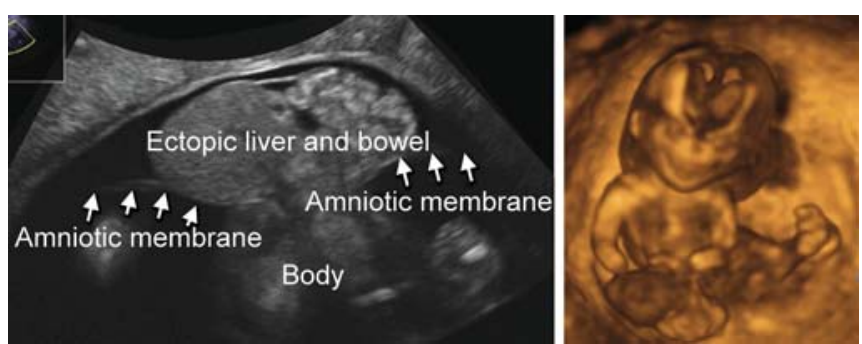

Fig. 48: Limb-body wall complex at 13 weeks of gestation. Left: $2 D$ image. Note the ectopic liver and bowels are outside amniotic membrane. Right: 3D reconstructed image. Ectopic abdominal organs and abnormal position of lower limbs are well-demonstrated
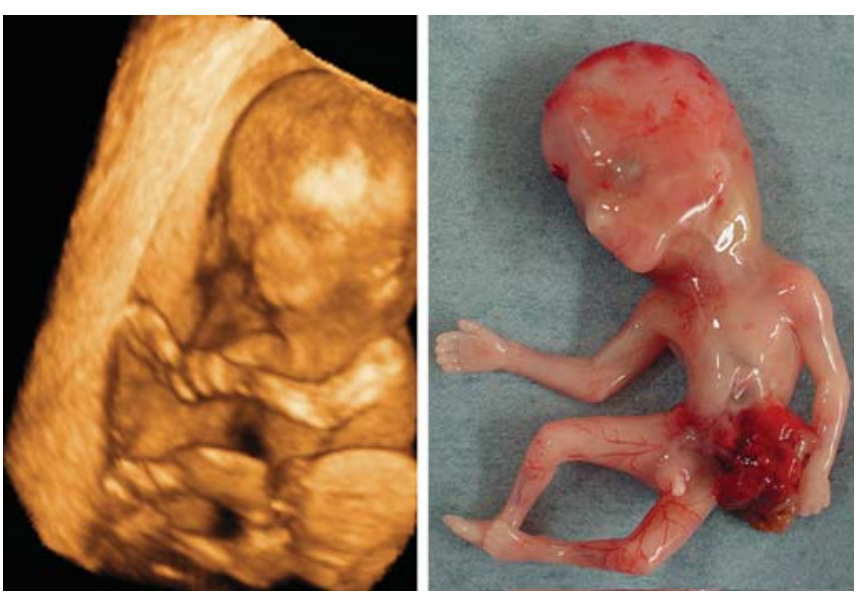

Fig. 49: Omphalocele at 12 weeks of gestation. (Left) 3D ultrasound image at 12 weeks and 5 days. (Right) macroscopic picture of aborted fetus. Hernial sac was ruptured at delivery
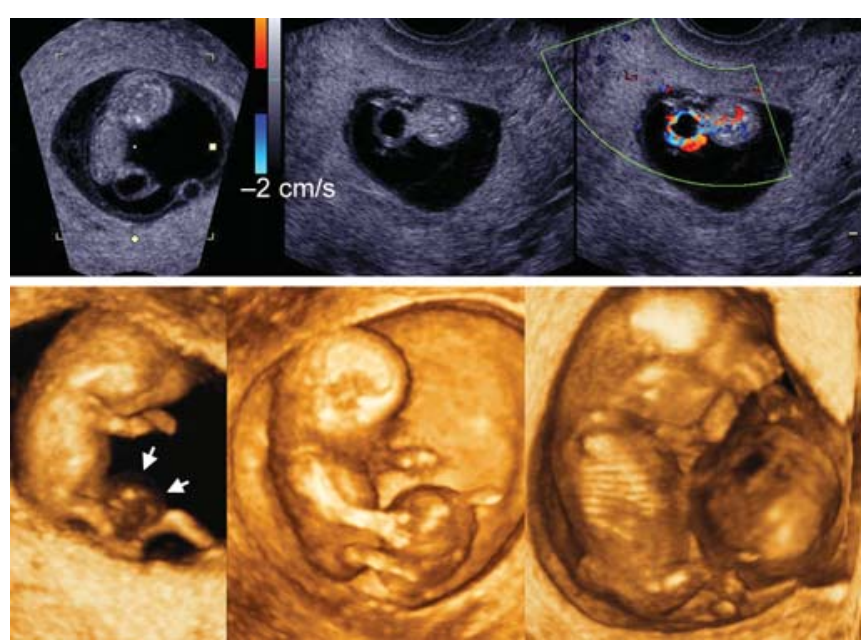

Fig. 50: Bladder extrophy in the first trimester. (Upper) Cystic formation between bilateral umbilical arteries. No bladder is visible inside of the fetus. (Lower) 3D ultrasound images at 10, 11 and 12 weeks from the left. Rapid increase in size of external bladder is clearly demonstrated

indicate that VAS at 18 to 30 weeks may not change the prognosis of renal function and that fetal surgery for obstructive uropathy should be performed only for the carefully selected patient who has severe oligohydramnios and 'normal' -appearing kidneys. ${ }^{42}$ To preserve renal function, however, earlier VAS may be preferable (Fig. 52).

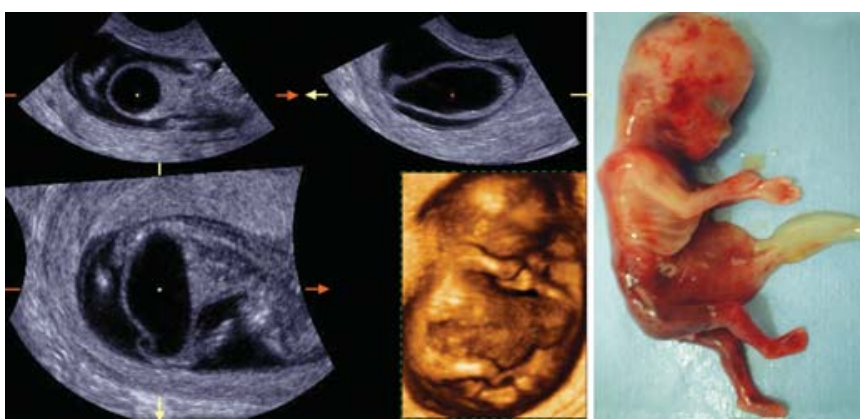

Fig. 51: Prune-Belly syndrome at 11 weeks of gestation. (Monochromatic figures) 3D orthogonal views of coronal (left upper), axial (middle upper) and sagittal (left lower) sections. Huge bladder of Prune-Belly shape and fragile abdominal wall are visible. (Middle lower) 3D imaging of the fetus (Right) macroscopic picture of aborted fetus
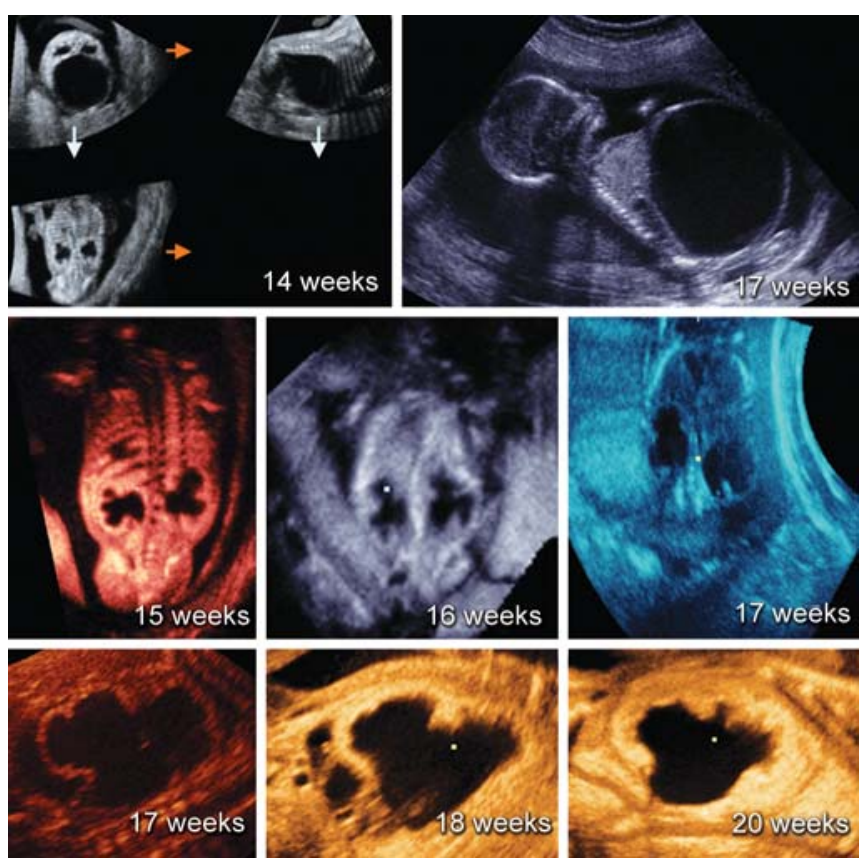

Fig. 52: Huge bladder before and after vesicoamniotic shunt operation. (Left upper) 3D orthogonal view at 14 weeks of gestation. Huge bladder and bilateral hydronephrosis are demonstrated. Abdominal wall is not fragile like Prune-Belly syndrome. (Right upper) sagittal image at 17 weeks before vesicoamniotic shunt (VAS). Bladder volume is $137.7 \mathrm{ml}$. (Middle figures) changing appearance of kidneys at 15,16 and 17 weeks from the left. Rapid thinning of renal parenchyma with progressive hydronephrosis is clearly demonstrated. (Lower figures) changing appearance of renal parenchyma (17,18 and 20 weeks from the left) after VAS operation performed at 17 weeks. Renal parenchyma thickness was rapidly recovered after VAS procedure with improvement of hydronephrosis

\section{CONCLUSION}

A s illustrated by many papers published recently, ${ }^{43-71}$ there has been an immense acceleration in the understanding of early human development. The anatomy and physiology of placental and embryonic development is a field where medicine exerts its greatest impact on early pregnancy at 
present time, and it opens fascinating aspects of normal and abnormal embryonic differentiation. Clinical assessment of those stages of growth rely heavily on 3D/4D sonography, one of the most promising forms of noninvasive diagnostics and embryological phenomenon, once matters for textbooks, are now routinely recorded with outstanding clarity. Some advances deserve the adjective 'breathtaking' including 4D parallel study of the structural and functional early human development.

During the first trimester of pregnancy, a unique and dramatic sequence of events occurs, defining the most critical and tenuous period of human development: The remarkable transformation of a single cell into a recognizable human being.

The possibility to describe the embryonic anatomy using the newer techniques has initiated a field called 'Sonoembryology'.

3D and 4D ultrasounds play an important role in the early diagnosis and assessment of fetal abnormalities. Indeed, this diagnostic tool has moved embryology from postmortem studies to the in vivo environment even in the first semester of pregnancy.

With modern trend of shifting prenatal diagnosis at the earliest possible gestation, it is not far that 11 to 14 weeks scan becomes the first minianomaly scan to diagnose severe structural abnormalities giving the parents reassurance of the fetal well being.

\section{REFERENCES}

1. Timor-Tritsch IE, Peisner DB, Raju S. Sonoembryology: An organ-oriented approach using a high-frequency vaginal probe. J Clin Ultrasound 1990;18(4):286-98.

2. Benoit B, Hafner $T$, K urjak A, K upesic S, B ekavac I, B ozek T. Three-dimensional sonoembryology. J Perinat $M$ ed 2002;30(1):63-73.

3. O'Rahilly R, M uller F. Prenatal ages and stages-measures and errors. Teratology 2000;61(5):382-84.

4. Pooh RK, Shiota K, K urjak A. Imaging of the human embryo with magnetic resonance imaging microscopy and highresolution transvaginal three-dimensional sonography: Human embryology in the 21st century. A m J Obstet Gynecol 2011 Jan;204(1):.1-77.

5. Kurjak A, Pooh RK, M erce LT, Carrera JM, Salihagic-K adic A, A ndonotopo W. Structural and functional early human development assessed by three-dimensional and fourdimensional sonography. Fertil Steril 2005;84(5):1285-99.

6. Kurjak $A$, Zudenigo $D$, Predanic $M, K$ upesic $S$. Recent advances in the D oppler study of early fetomaternal circulation. J Perinat Med 1993;21:419-39.

7. Kurjak A, Schulman H, Predanic A, Predanic M, Kupesic S, Zalud I. Fetal choroid plexus vascularization assessed by color flow ultrasonography. J Ultrasound M ed 1994;13:841-44.

8. Pooh RK, A ono T. Transvaginal power Doppler angiography of the fetal brain. Ultrasound Obstet Gynecol 1996;8:417-21.

9. Chaoui $R$, Levaillant J M, B enoit B, Faro C, Wegrzyn P, $\mathrm{Nicolaides} \mathrm{KH}$. Three-dimensional sonographic description of abnormal metopic suture in second- and third-trimester fetuses. Ultrasound Obstet Gynecol 2005;26:761-64.
10. Kim M S, J eanty P, Turner C, B enoit B. Three-dimensional sonographic evaluations of embryonic brain development. J Ultrasound M ed 2008;27:119-24.

11. Hata T, Dai SY, Kanenishi K, Tanaka H. Three-dimensional volume-rendered imaging of embryonic brain vesicles using inversion mode. J Obstet Gynaecol Res 2009;35:2:258-61.

12. Jauniaux E, Gulbis B, Burton GJ. The human first trimester gestational sac limits rather than facilitates oxygen transfer to the foetus: A review. Placenta 2003;24(17):S86-S93.

13. Kucuk T, Duru NK, Y enen MC, Dede M, Ergûn A, Baser I. $Y$ olk sac size and shape as predictors of poor pregnancy outcome. J Perinat M ed 1999;27:316-20.

14. Lindsay DJ, Lovett IS, Lyons EA, Levi CS, Zheng XH, Holt SC, et al. Y olk sac diameter and shape at endovaginal US: Predictors of pregnancy outcome in the first trimester. Radiology 1992;183:115-18.

15. Blaas HG, Eik-N es SH, I saksen CV. The detection of spina bifida before 10 gestational weeks using two- and three-dimensional ultrasound. U Itrasound O bstet Gynecol 2000;16(1):25-29.

16. Nicolaides K H. Nuchal translucency and other first-trimester sonographic markers of chromosomal abnormalities. A m J Obstet Gynecol 2004;191:45-67.

17. Cicero S, Curcio P, Papageorghiou A, Sonek J, Nicolaides K. A bsence of nasal bone in fetuses with trisomy 21 at 11 to 14 weeks of gestation: An observational study. Lancet 2001;358: 1665-67.

18. Zoppi M A, Ibba R M , A xiana C, Floris M, M anca F, M onni G. A bsence of fetal nasal bone and aneuploidies at first-trimester nuchal translucency screening in unselected pregnancies. Prenat Diagn 2003;23:496-500.

19. Cicero $S, R$ embouskos $G, V$ andecruys $H, H$ ogg $M, N$ icolaides $\mathrm{KH}$. L ikelihood ratio for trisomy 21 in fetuses with absent nasal bone at the 11 to 14-weeks scan. U Itrasound Obstet Gynecol 2004;23:218-23.

20. Cicero S, A vgidou K, Rembouskos G, Kagan K O, Nicolaides $\mathrm{KH}$. N asal bone in first-trimester screening for trisomy 21 . A m J Obstet Gynecol 2006;195:109-14.

21. Rembouskos $G$, Cicero $S$, L ongo $D, V$ andecruys $H, N$ icolaides $\mathrm{KH}$. A ssessment of the fetal nasal bone at 11 to 14 weeks of gestation by three-dimensional ultrasound. Ultrasound $\mathrm{Obstet}$ Gynecol 2004;23:232-36.

22. B enoit $B, C$ haoui $R$. Three-dimensional ultrasound with maximal mode rendering: A novel technique for the diagnosis of bilateral or unilateral absence or hypoplasia of nasal bones in secondtrimester screening for Down syndrome. Ultrasound Obstet Gynecol 2005;25:19-24.

23. Cicero S, Curcio P, Rembouskos G, Sonek J, Nicolaides KH. $M$ axillary length at 11 to 14 weeks of gestation in fetuses with trisomy 21. UItrasound Obstet Gynecol 2004;24:19-22.

24. Teoh M, M eagher S. First-trimester diagnosis of micrognathia as a presentation of Pierre Robin syndrome. Ultrasound Obstet Gynecol 2003;21:616-18.

25. Tsai MY, Lan KC, Ou CY, Chen JH, Chang SY, Hsu TY. A ssessment of the facial features and chin devel opment of fetuses with use of serial three-dimensional sonography and the mandibular size monogram in a Chinese population. A m J Obstet Gynecol 2004;190(2):541-46.

26. F rancis PJ, B erry V, B hattacharya SS, M oore A T. The genetics of childhood cataract. J M ed G enet 2000;37:481-88.

27. Thut CJ, Rountree RB, H wa M, Kingsley DM . A large-scale in situ screen provides molecular evidence for the induction of eye anterior segment structures by the develop- ing lens. Dev Biol 2001;231:63-76. 
Three-dimensional/Four-dimensional Sonography moved Prenatal Diagnosis of Fetal Anomalies

28. K arkinen-Jääskeläinen $M$, Saxena $L, V$ aheri $A$, L einikki $P$. Rubella cataract in vitro: Sensitive period of the developing human lens. J Exp Med 1975;141:1238-48.

29. Romain M, A woust J, Dugauquier $C, V$ an M aldergem L. Prenatal ultrasound detection of congenital cataract in trisomy 21. Prenat Diagn 1999 Aug;19(8):780-82.

30. Pedreira DA, Diniz EM , Schultz R, Faro LB, Zugaib M . Fetal cataract in congenital toxoplasmosis. U Itrasound O bstet Gynecol 1999 A pr;13(4):266-67.

31. Daskalakis G, A nastasakis E, Lyberopoulos E, A ntsaklis A. Prenatal detection of congenital cataract in a fetus with Lowe syndrome. J Obstet Gynaecol 2010;30(4):409-10.

32. Reches $A, Y$ aron $Y, B$ urdon $K$, Crystal-Shalit $O, K$ idron $D$, $M$ alcov $M$, et al. Prenatal detection of congenital bilateral cataract leading to the diagnosis of Nance-Horan syndrome in the extended family. Prenat Diagn 2007;27(7):662-64.

33. L éonard A, B ernard P, Hiel AL, Hubinont C. Prenatal diagnosis of fetal cataract: Case report and review of the literature. Fetal Diagn Ther 2009;26(2):61-67.

34. Bolitho DG. Hand, Congenital hand deformities. Emedicine 2006. http://www.emedicine.com/plastic/TOPIC 298.HTM .

35. Carbillon L, Seince N, L argillière C, B ucourt M , U zan M . Firsttrimester diagnosis of sirenomelia. A case report. Fetal Diagn Ther 2001;16(5):284-88.

36. M onteagudo A, M ayberry P, Rebarber A, Paidas M, TimorTritsch IE. Sirenomelia sequence: First-trimester diagnosis with both two- and three-dimensional sonography. J U Itrasound M ed 2002;21:915-20.

37. Schiesser M, Holzgreve W, Lapaire O, Willi N, L üthi H, L opez $R$, et al. Sirenomelia, the mermaid syndrome- - detection in the first trimester. Prenat Diagn 2003;23:493-95.

38. Dugoff $L$, Thieme $G$, Hobbins JC. First trimester prenatal diagnosis of chondroectodermal dysplasia (Ellis-van Creveld syndrome) with ultrasound. UItrasound Obstet Gynecol 2001;17:86-88.

39. Percin EF, Guvenal T, Cetin A, Percin S, G oze F, A rici S. Firsttrimester diagnosis of Robinow syndrome. Fetal Diagn Ther 2001;16:308-11.

40. Doyle N M, L ally KP. The CDH Study Group and advances in the clinical care of the patient with congenital diaphragmatic hernia. Semin Perinatol 2004;28:174-84.

41. Daskalakis G, A nastasakis E, Souka A, M anoli A, Koumpis C, A ntsaklis A. First trimester ultrasound diagnosis of congenital diaphragmatic hernia. J Obstet Gynaecol Res 2007;33:870-72.

42. Holmes N, Harrison M R, Baskin LS. Fetal surgery for posterior urethral valves: Long-term postnatal outcomes. Pediatrics 2001;108:1-7.

43. Pooh RK. Contribution of transvaginal high-resolution ultrasound in fetal neurology. Donald School J Ultrasound O bstet Gynecol 2011;2(5):93-99.

44. Comas C, Echevarria M, Rodriguez I, Sabria, Serra B. A nalysis of quality of nuchal translucency measurements. D onald School J Ultrasound Obstet Gynecol 2011;2(5):127-32.

45. Pooh RK, K urjak A. Fetal N eurology. J aypee B rothers: N ew Delhi 2009.

46. Kurjak A, Chervenak FA. Donald School Textbook of Ultrasound in Obstetrics and Gynecology (3rd ed). Jaypee Brothers: New Delhi 2011.

47. Kurjak A, A zumendi G, A ndonotopo W, Salihagic-Kadic A. Three- and four-dimensional ultrasonography for the structural and functional evaluation of the fetal face. A m J Obstet Gynecol 2007;196:16-28.
48. Pooh RK, Kurjak A. Recent advances in $3 D$ assessment of various fetal anomalies. Donald School J Ultrasound Obstet Gynecol 2009;3(3):1-25.

49. L ausin I, Kurjak A. The early human development: A dvances in its visualisation. Gynaecol Perinatol 2009;18(2):76-87.

50. Pooh RK, Kurjak A. 3D and 4D sonography and magnetic resonance in the assessment of normal and abnormal CNS development: A Iternatives or complementaries. J Perinat M ed 2011;39(1):3-13.

51. Kurjak A, K upesic S, Di Renzo GC, Pooh RK, K os M, Hafner $T$. Recent advances in perinatal sonography. Prenat $N$ eonat $M$ ed 1998;3:194-207.

52. Pooh RK. Early detection of fetal abnormality. D onald School J Ultrasound Obstet Gynecol 2005;2:74-83.

53. Pooh RK, Kurjak A. Normal and abnormal early human structural development. In: K urjak A, A zumendi G (Eds). The Fetus in Three-Dimensions: Imaging, Embryology and Fetoscopy. Informa: London 2007;83-98.

54. Pooh RK, Kurjak A, Tikvica A. Normal and abnormal brain vascularity. In: Pooh RK, Kurjak A (Eds). Fetal Neurology. J aypee Brothers: N ew Delhi 2009;39-58.

55. Pooh RK, Kurjak A. Neuroscan of normal and abnormal vertebrae and spinal cord. In: Pooh RK, K urjak A (Eds). Fetal Neurology. Jaypee B rothers: New Delhi 2009;141-59.

56. Pooh RK, Shiota K, Kurjak A. Three-dimensional sonoembryology. In Kurjak A, Chervenak FA (Eds). Donald School Textbook of U Itrasound in Obstetrics and Gynecology (3rd ed). J aypee Brothers: N ew D elhi 2011:540-58.

57. Pooh RK, Kurjak A. 3D ultrasound in detection of fetal anomalies. In: K urjak A, Chervenak FA (Eds). Donald School Textbook of U Itrasound in O bstetrics and Gynecology (3rd ed). J aypee Brothers: N ew Delhi 2011:621-39.

58. E brashy A, El K ateb A, M omtaz M, El Sheikhah A, A boulghar $M M$, Ibrahim $M$, et al. 13-14-week fetal anatomy scan: $A$ 5-year prospective study. U Itrasound Obstet Gynecol 2010;35:292-96.

59. Tonni G, Ventura A, Bonasoni M P. A crania/encephalocele sequence (exencephaly) associated with $92, X X X X$ karyotype: Early prenatal diagnosis at $9+5$ weeks by $3 D$ transvaginal ultrasound and coelocentesis. Congenital Anomalies 2009;49:113-15.

60. B ecker R, W egner RD. Detailed screening for fetal anomalies and cardiac defects at the 11-13-week scan. U Itrasound O bstet Gynecol 2006;27:613-18.

61. Carvalho M HB, Brizot M L, L opes LM , Chiba CH, M iyadahira $S$, Zugaib M. Detection of fetal structural abnormalities at the 11 to 14 weeks ultrasound scan. Prenat Diagn 2002;22:1-4.

62. Saltvedt S, A Imstrom H, K ublickas M, V alentin L, G runewald C. D etection of malformations in chromosomal ly normal fetuses by routine ultrasound at 12 or 18 weeks of gestation-a randomised controlled trial in 39572 pregnancies. BJOG 2006;113:664-74.

63. Sepulveda W, Wong AE, Fauchon DE. Fetal spinal anomalies in a first-trimester sonographic screening program for aneuploidy. Prenat Diagn 2011;31:107-14.

64. A ntsaklis A, A nastasakis E, K omita O, Theodora M, Hiridis P, Daskalakis G. First trimester 3D volumetry. A ssociation of the gestational volumes with the birth weight. J M atern Fetal Neonatal M ed 2011 A ugust; 24(8):1055-59.

65. Tonni G, Ventura A, Centini G, De Felice C. First trimester three-dimensional transvaginal imaging of alobar holoprosencephaly associated with proboscis and hypotelorism (ethmocephaly) in a 46, XX fetus. Congenit A nom (K yoto) 2008;48(1):51-55. 
66. A bu-Rustum RS, Daou L, A bu-Rustum SE. Role of firsttrimester sonography in the diagnosis of aneuploidy and structural fetal anomalies. J UItrasound M ed 2010; 29:1445-52.

67. Souka AP, Pilalis A, Kavalakis I, A ntsaklis P, Papantoniou N, $M$ esogitis $S$, et al. Screening for major structural abnormalities at the 11 to 14 weeks ultrasound scan. A m J Obstet Gynecol 2006;194:393-96.

68. Ghi T, Pilu G, Svelli L, Segata M, Bovicelli L. Sonographic diagnosis of congenital anomalies during the first trimester. Placenta 2003;24:S84-S87.

69. Bronshtein M, Zimmer EZ, Blazer S. The utility of detailed first trimester ultrasound examination in abnormal fetal nuchal translucency. Prenat Diagn 2008;28:1037-41.

70. Sciaky-Tamir Y, Cohen SM, Hochner-Cel nikier D, V al sky DV, $M$ essing B , Y agel S. Three-dimensional power Doppler (3D PD) ultrasound in the diagnosis and follow-up of fetal vascular anomalies. A m J Obstetr Gynecol 2006;194:274-81.

71. Dane B, Dane C, Sivri D, Kiray M, Cetin A, Y ayla M. Ultrasound screening for fetal major abnormalities at 11 to 14 weeks. A cta Obstet Gynecol Scand 2007;86(6):666-70.

\section{ABOUT THE AUTHORS}

\section{Ritsuko K Pooh}

CRIFM R esearch I nstitute of F etal M edicine and PM C, O saka, J apan

\section{Asim Kurjak (Corresponding Author)}

Professor, Department of Obstetrics and Gynecology and Dean of Faculty of $\mathrm{H}$ ealth Sciences, Dubrovnik International U niversity Dubrovnik 20000, Croatia, e-mail: asim.kurjak@ public.carnet.hr 